\title{
The C-MYC-interacting proapoptotic tumor suppressor BIN1 is a transcriptional target for E2F1 in response to DNA damage
}

\author{
EK Cassimere ${ }^{1,2,3}$, S Pyndiah ${ }^{1}$ and D Sakamuro ${ }^{*, 1,2}$
}

The E2F1 transcription factor, which was originally identified as a cell-cycle initiator, mediates apoptosis in response to DNA damage. As E2F1-induced apoptosis is an attractive mechanism for cancer therapy, it is critical to fully elucidate its effector pathways. Here, we show that the C-MYC-interacting proapoptotic tumor suppressor, BIN1, is transcriptionally activated by E2F1 and mediates E2F1-induced apoptosis in response to DNA damage. Acting through the DNA-binding and transactivation domains, ectopically expressed E2F1 activated the human BIN1 promoter, which contains canonical E2F-recognition sites. Conversely, depletion of E2F1 by small interfering RNA or germline deletion led to BIN1 deficiency. DNA-damaging agents (which included etoposide) increased BIN1 levels, unless E2F1 was deficient. Moreover, endogenous E2F1 protein interacted directly with the BIN1 gene promoter in chromatin, particularly after etoposide treatment. Notably, suppression of BIN1 expression using an antisense (AS) technique attenuated the cell death mediated by E2F1 and etoposide. Although the p53 tumor suppressor, its sibling protein p73, and caspases are well-known E2F1 effectors for DNA damage-induced apoptosis, AS-BIN1 did not compromise their apoptotic functions. Our results collectively suggest that BIN1 is a novel transcriptional target of E2F1 that triggers a unique mode of cell death in response to DNA damage.

Cell Death and Differentiation (2009) 16, 1641-1653; doi:10.1038/cdd.2009.98; published online 24 July 2009

The E2F1 transcription factor was initially identified as an adenoviral E2 promoter-binding cellular Factor-1 that is induced by adenoviral E1A oncoprotein. ${ }^{1}$ Ectopic expression of $E 2 F 1$ is sufficient to promote $G_{1} / S$ phase transition in the cell cycle. ${ }^{2}$ Moreover, forced expression of E2F1 confers oncogenic properties to immortalized rodent fibroblasts ${ }^{2}$ and enhances tumor formation both in vitro and in vivo, particularly after p53 deletion. ${ }^{3}$ Furthermore, deregulated E2F1 via inactivation of the retinoblastoma (RB) tumor suppressor is a hallmark of human malignancies. ${ }^{4}$ These facts suggest that E2F1 is a protooncogene.

Subsequent studies established that E2F1 acts as an inducer of apoptosis. ${ }^{5-9}$ Under certain conditions, deregulated E2F1 triggers apoptosis via both p53-dependent and p53independent mechanisms. To induce p53-dependent apoptosis, E2F1 activates the expression of $\mathrm{p} 14 / \mathrm{p} 19^{\mathrm{ARF}}$ to stabilize p53. ${ }^{5}$ Alternatively, E2F1 directly activates various proapoptotic genes or, conversely, inactivates several antiapoptotic genes. ${ }^{6,7}$ Additionally, germline deletion of E2f1 in mice leads to the formation of various tumors, presumably resulting from the lack of E2f1-induced apoptosis. ${ }^{8,9}$ In view of its potential significance as a chemotherapeutic target, particularly in p53-deficient cancers, it is critical to clarify the proapoptotic effector(s) of E2F1 in response to DNA damage.
The bridging integrator-1 (BIN1) protein was originally identifie $\bar{d}$ as a c-MYC-interacting proapoptotic tumor suppressor. ${ }^{10}$ Several splice variants of BIN1 harbor a MYCbinding domain (MBD), thus retaining the ability to physically interact with and inhibit the oncogenic functions of C-MYC. ${ }^{10-12}$ The BIN1-c-MYC interaction mediates c-MYC-induced apoptosis, at least partly. ${ }^{13}$ Interestingly, BIN1-induced cell death is not compromised by dysfunctional p53, caspase inhibition, and/or overexpression of BCL-2, ${ }^{12,14}$ which suggests that BIN1's proapoptotic property could be useful for the eradication of cancer cells where p53 and/or caspases are frequently dysfunctional.

In this study, we present evidence that the human BIN1 gene is a novel transcriptional target of E2F1 for caspaseindependent apoptosis in response to DNA damage. Genotoxic agents, which stabilize E2F1 protein, ${ }^{15}$ upregulated BIN1 levels. Conversely, depletion of E2F1 led to the downregulation of BIN1 expression. Interestingly, BIN1 ablation markedly attenuated the cell death mediated by E2F1, and rendered cancer cells resistant to DNA damage; however, other established E2F1 proapoptotic effectors, which included p53, p73, and caspases, induced apoptosis irrespective of BIN1 status; hence, we propose that BIN1 is a novel proapoptotic effector of E2F1, particularly after DNA damage.

\footnotetext{
${ }^{1}$ Division of Cancer Biology, Department of Pathology, School of Medicine and Stanley S. Scott Cancer Center, Louisiana State University Health Sciences Center, New Orleans, LA, USA and ${ }^{2}$ Biochemistry and Molecular Biology Graduate Program, Purdue University and Purdue Cancer Center, West Lafayette, IN, USA

${ }^{*}$ Corresponding author: D Sakamuro, Department of Pathology and Stanley S. Scott Cancer Center, Louisiana State University Health Sciences Center, 533 Bolivar Street, CSRB 748-A, New Orleans, LA 70112, USA. Tel: 504568 8256; Fax: 504568 2932; E-mail: dsakam @ Isuhsc.edu

${ }^{3}$ Current address: Department of Integrative Biology and Pharmacology, The University of Texas Health Science Center, Houston, TX 77030, USA Keywords: BIN1; E2F1; DNA damage response; apoptosis

Abbreviations: BIN1, bridging integrator 1; AS, antisense; ChIP, chromatin immunoprecipitation; HA, hemagglutinin; IRES, internal ribosome entry site; MEF, mouse embryonic fibroblast; 4-OHT, 4-hydroxy tamoxifen; qRT-PCR, quantitative real-time reverse-transcriptase polymerase chain reaction; siRNA, small interfering RNA Received 14.1.09; revised 29.5.09; accepted 16.6.09; Edited by JC Marine; published online 24.7.09
} 


\section{Results}

Genotoxic stresses increased the levels of BIN1 regardless of the p53 status. Because of the frequent losses of BIN1 in various cancer cell lines and cancer tissues that are often resistant to apoptosis, ${ }^{10,11,16-19}$ endogenous BIN1 may be coupled to cancer sensitivity to apoptosis. In view of that, we assumed that proapoptotic stress conditions, which include genotoxic stress, might upregulate BIN1 expression. As the p53 tumor suppressor is mostly responsible for the induction of apoptosis in response to DNA damage, we determined whether there is a correlation between endogenous $\mathrm{p} 53$ status and BIN1 expression after DNA damage. To do this, we cultured the LNCaP prostate carcinoma cell line (which expresses wild-type (wt)-p53), the U2OS osteosarcoma line (which also expresses wt-p53), and the SAOS2 osteosarcoma line (which does not express p53) in the presence of various DNA-damaging agents and detected endogenous BIN1 levels.

We observed a dose-dependent increase in the levels of endogenous BIN1 protein in the presence of a chemotherapeutic agent, which included etoposide, adriamycin, and cisplatin, regardless of p53 expression status (Figure 1a). Consistently, $\gamma$-irradiation also augmented endogenous BIN1 expression, which was reversed specifically by cotransfection of small interfering RNA (siRNA) for BIN1 (Figure 1b). These data suggest that cellular machinery sensitive to DNA damage upregulates BIN1 gene. Consistent with this theory, luciferase reporter assays using a human BIN1 promoter $(-774 /+112)$-driven reporter construct (named BIN1-Luc) ${ }^{20,21}$ confirmed that the BIN1 promoter activity was enhanced with increasing doses of etoposide in LNCaP cells (Figure 1c) and SAOS2 cells (data not shown). We concluded that BIN1 is a DNA damage-sensitive gene that is activated by a p53-independent mechanism.
The human BIN1 promoter displayed characteristics of an E2F target gene. To obtain a better insight into the mechanism by which DNA damage increases the BIN1 promoter activity, we analyzed the nucleotide sequence of an $886 \mathrm{bp}$ genomic DNA fragment encompassing the human BIN1 promoter region $(-774 /+112) .{ }^{20}$ We used the TFSEARCH program, a computer algorithm available at http://mbs.cbrc.jp/research/db/TFSEARCH.html, and identified the 22 potential transcription factors that may bind directly to and modulate the BIN1 promoter activity. Interestingly, E2F was the only BIN1-inducible transcription factor that participates in both tumor suppression and DNA damage-induced apoptosis (Supplementary Table S1). Four sequences located at positions $-576,-515$, -295 , and -284 of the human BIN1 promoter displayed significant homology with the canonical E2F recognition motif, $\operatorname{TTT}(\mathrm{G} / \mathrm{C})(\mathrm{G} / \mathrm{C}) \mathrm{CGC}^{22}$ (Figure 2a); these putative E2F-binding sites were designated $\operatorname{E2F}(\alpha), \operatorname{E} 2 F(\beta), \operatorname{E} 2 F(\gamma)$, and $\operatorname{E2F}(\delta)$, respectively (Figure $2 b$ ). The $\operatorname{E2F}(\gamma)$ and $\mathrm{E} 2 \mathrm{~F}(\delta)$ sites lie in opposite orientations and partially overlap, which represents an $\operatorname{E} 2 F(\gamma / \delta)$ site. Scanning of the mouse and rat Bin1 promoter sequences further revealed the presence of at least one canonical E2F recognition motif (EKC and DS, unpublished observations), which implies an evolutionary conserved role for E2F in BIN1 gene regulation.

E2F1-inducible factors activated the BIN1 promoter. To test if E2F1 is involved in the induction of the BIN1 promoter activity, the adenovirus E1A-13S expression vector, p1Aneo, ${ }^{10}$ was transiently cotransfected with BIN1-Luc in LNCaP cells. E1A oncoprotein induces E2F1 via inactivation of the RB pocket protein. ${ }^{1,4}$ Overexpression of E1A significantly activated the BIN1 promoter (Figure 2c). To confirm potential involvement of E2F1 in BIN1 induction further, we
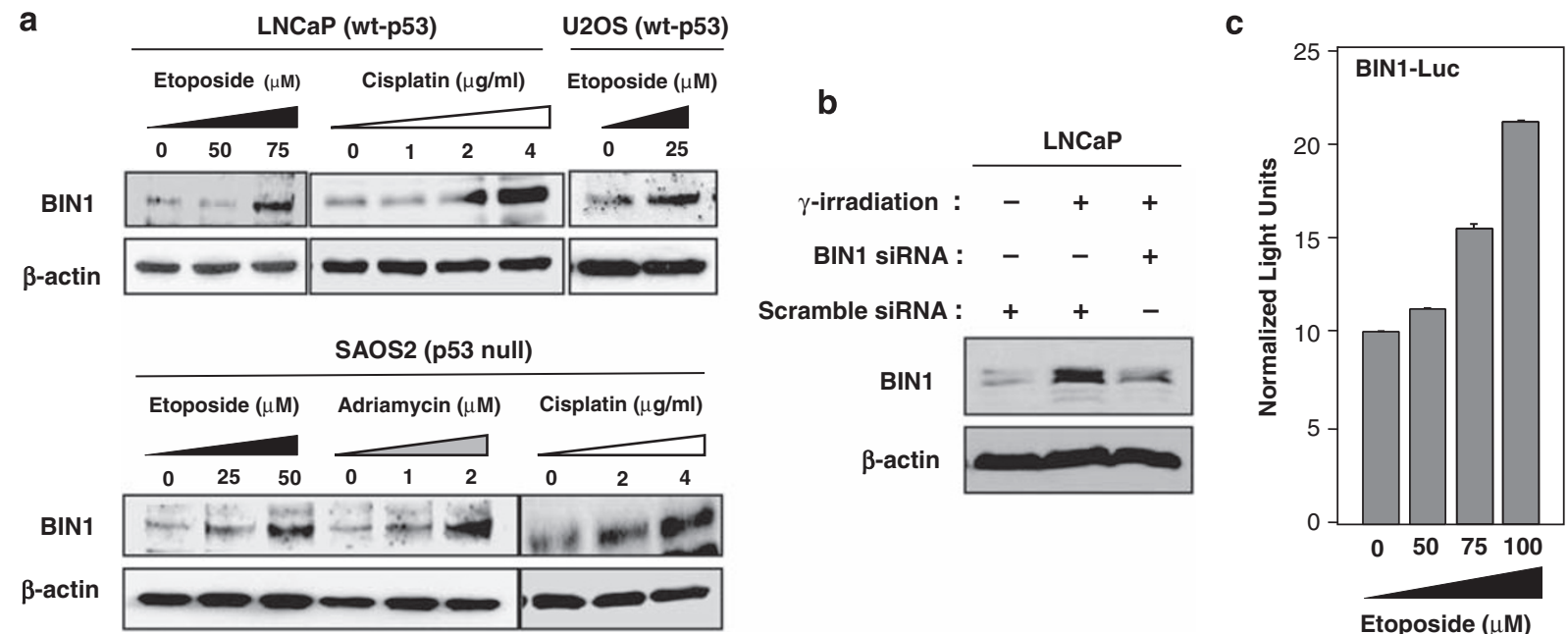

Etoposide $(\mu \mathrm{M})$

Figure 1 DNA-damaging agents induced endogenous BIN1 expression and promoter activity. (a) Western blot analysis of endogenous BIN1 protein expressed in LNCaP, U2OS, and SAOS2 cells pretreated with the indicated doses of etoposide, adriamycin, or cisplatin for $24 \mathrm{~h}$. DMSO was used as the filler. Under these culture conditions, limited or no cell damage was observed (data not shown). $\beta$-Actin was used as the internal loading control. (b) Approximately $24 \mathrm{~h}$ after transfection of scramble siRNA $(2.0 \mu \mathrm{g})$ or BIN1 siRNA $(2.0 \mu \mathrm{g})$, LNCaP cell suspensions $\left(1.0 \times 10^{6} \mathrm{cells} / \mathrm{ml}\right)$ in PBS were $\gamma$-irradiated at a $50 \mathrm{~Gy}$ single dose for $200 \mathrm{~s}$. Precleared lysates were used for western blot analysis with an anti-BIN1 (2F11) antibody. $\beta$-Actin was used as the internal loading control. (c) Approximately $24 \mathrm{~h}$ after transfection of BIN1-Luc, LNCaP cells were cultured with increasing doses of etoposide for $24 \mathrm{~h}$. Each raw luciferase activity value was normalized to cotransfected $\beta$-galactosidase activity. Three independent transfections were performed and data presented are mean \pm standard error 
a

\begin{tabular}{|c|c|c|c|}
\hline \multicolumn{3}{|c|}{ E2F-recognition consensus motif: } & TTTSSCGC \\
\hline $\begin{array}{c}\text { E2F1 apoptotic } \\
\text { target gene promoters }\end{array}$ & $\begin{array}{l}\text { c-myc } \\
\text { p14ARF } \\
\text { Apaf1 } \\
\text { p73 }\end{array}$ & $\begin{array}{l}\text { antisense } \\
\text { antisense } \\
\text { sense } \\
\text { sense } \\
\text { antisense } \\
\text { antisense }\end{array}$ & $\begin{array}{l}\text { TTTCCCGC } \\
\text { TTTCCCGC } \\
\text { CTTGGCGT } \\
\text { CTTCCCGC } \\
\text { TTTGGCGC } \\
\text { TTAGCGCC }\end{array}$ \\
\hline Human BIN1 gene promoter & $\begin{array}{l}\operatorname{E} 2 \mathbf{F}(\alpha) \\
\operatorname{E} 2 \mathbf{F}(\beta) \\
\operatorname{E} 2 \mathbf{F}(\gamma)^{\star} \\
\operatorname{E} 2 \mathbf{F}(\delta)^{\star}\end{array}$ & $\begin{array}{l}\text { sense } \\
\text { antisense } \\
\text { sense } \\
\text { antisense }\end{array}$ & $\begin{array}{l}\text { TTAGGCGC } \\
\text { TTTCGCCC } \\
\text { TTTGCGGG } \\
\text { TTTCCCCG }\end{array}$ \\
\hline
\end{tabular}

b

BIN1-Luc
C

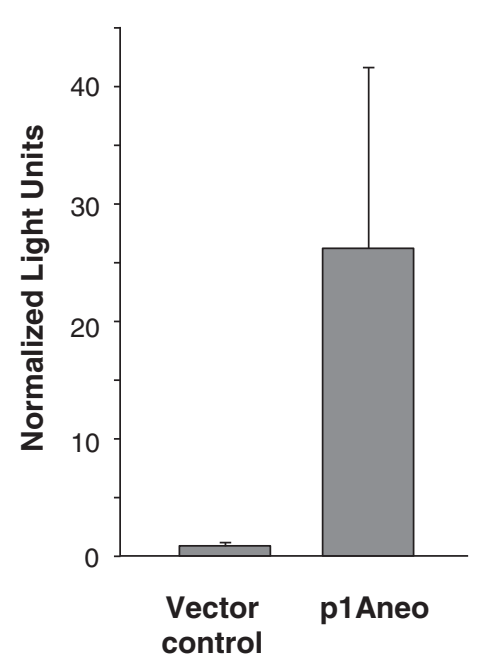

d

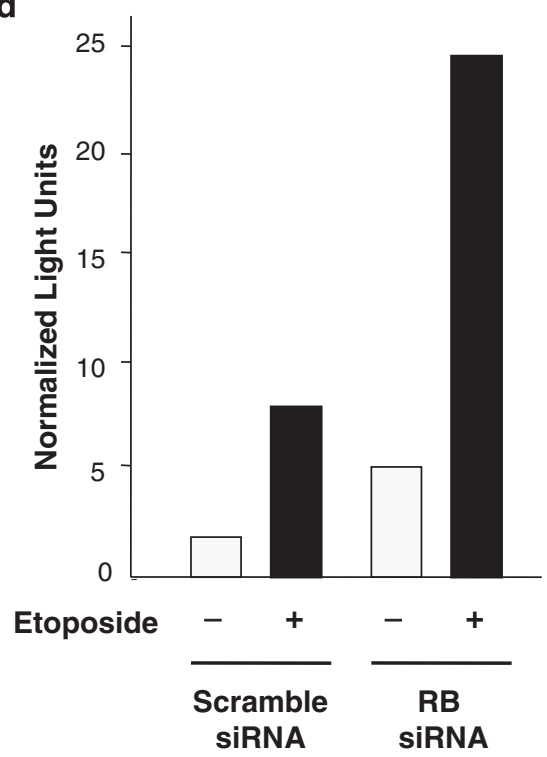

Figure 2 The human BIN1 promoter displayed characteristics of an E2F target gene. (a) E2F-binding consensus motifs identified on several E2F1 proapoptotic target gene promoters and the human $B I N 1$ gene promoter. The $\operatorname{E2F}(\alpha)$ and $\operatorname{E2} F(\beta)$ sites were predicted using the TFSEARCH program, whereas the $\operatorname{E} 2 \mathrm{~F}(\gamma)$ and $\operatorname{E2F}(\delta)$ sites, which overlap and are highlighted with an asterisk $\left({ }^{*}\right)$, were identified by visual inspection. All putative E2F recognition sequences on the human BIN1 promoter were aligned with other established proapoptotic E2F1 recognition sequences. Nucleotides that did not match the E2F consensus motif (TTTSSCGC, $\mathrm{S}=\mathrm{G} / \mathrm{C})^{22}$ are depicted in white. (b) Schematic diagram of the human BIN1 promoter in a pGL2-basic luciferase reporter construct (BIN1-Luc). The bent thin arrow at nucleotide position +1 represents the transcription start site. Open circles indicate putative E2F recognition sites. Normalized luciferase light units of BIN1-Luc in LNCaP cells cotransfected with (c) p1Aneo and (d) RB siRNA (or scramble siRNA). Approximately $24 \mathrm{~h}$ after transfection of RB siRNA (or scramble siRNA), LNCaP cells were cultured in the presence $(+)$ and absence $(-)$ of etoposide for $24 \mathrm{~h}$

used RB siRNA, which releases endogenous E2F1 activity, ${ }^{21}$ and etoposide, which stabilizes E2F1 protein via phosphorylation mediated by the ataxia telangiectasia-mutated (ATM) kinase. $^{15}$ As predicted, BIN1-Luc activity was increased by transient transfection of RB siRNA, which was augmented further in the presence of etoposide (Figure 2d). Our data suggest that the human BIN1 promoter is likely to be activated by E2F1 after DNA damage or in response to oncogenic stress that inactivates RB.
E2F1 activated the BIN1 promoter in various cell lines. To determine whether E2F1 directly activates BIN1 promoter, a hemagglutinin (HA)-tagged E2F1 expression vector (CMV-HA-E2F1) was cotransfected with BIN1-Luc. Ectopically expressed E2F1 increased endogenous BIN1 levels (Figure $3 a$ ) and BIN1 promoter activity in a dosedependent manner (Figure 3b). Furthermore, DNA bindingdeficient mutant E2F1 expression vector (CMV-E2F1 $\left.1_{\mathrm{E} 132}\right)$ and a transactivation domain-deleted E2F1 vector 
a

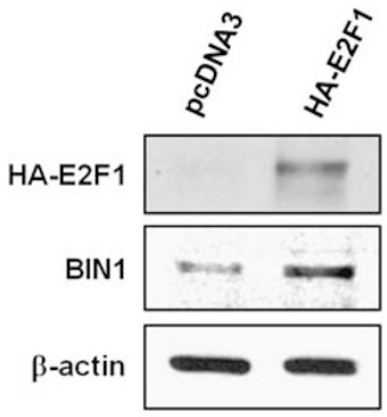

b
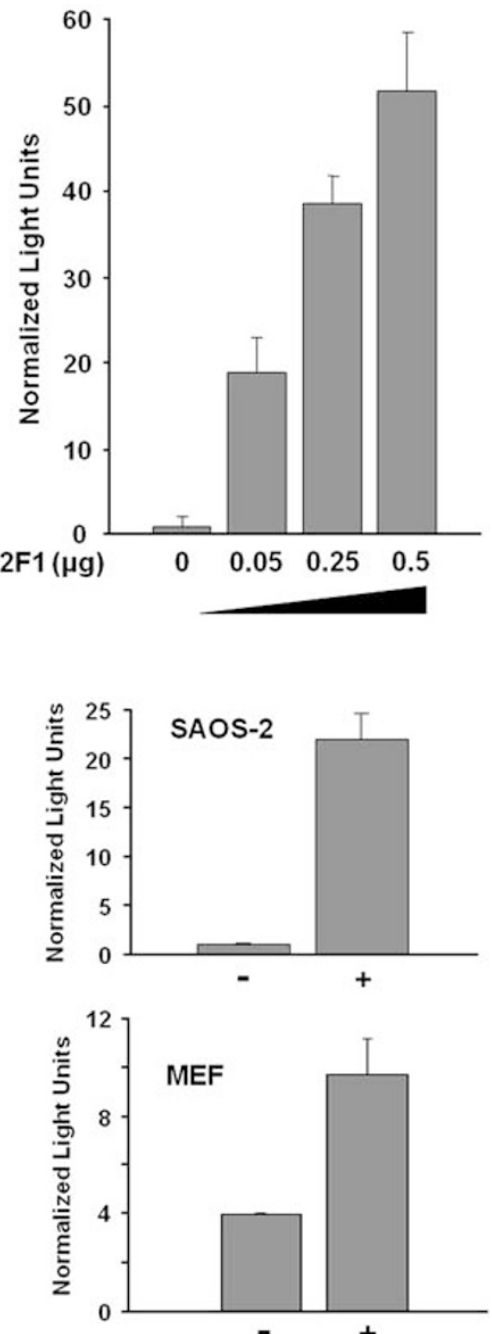

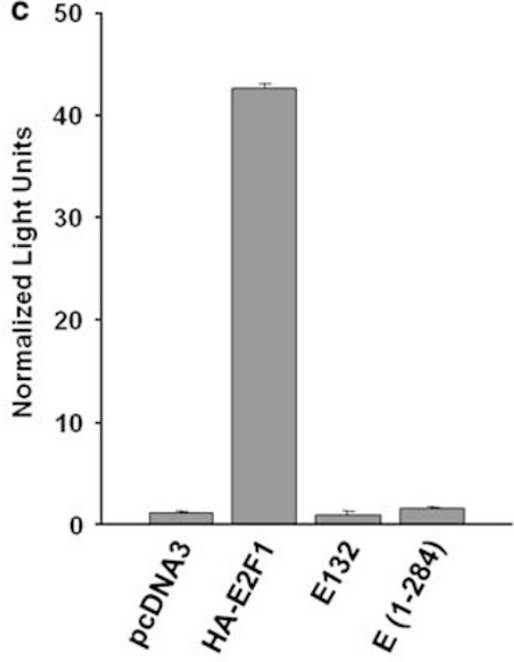

e

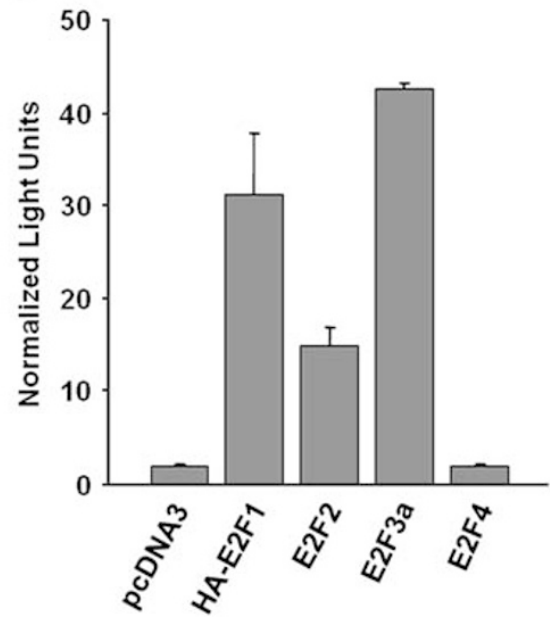

Figure 3 Ectopically expressed E2F1 activated the human BIN1 promoter. (a) Western blot analysis of transfected HA-E2F1 (CMV-HA-E2F1) with an anti-HA antibody and endogenous BIN1 proteins with an anti-BIN1 (2F11) antibody in LNCaP cells. $\beta$-Actin was used as the internal loading control. (b) Dose-dependent effect of the transient transfection of CMV-HA-E2F1 $(0-0.5 \mu \mathrm{g})$ on BIN1-Luc $(1.0 \mu \mathrm{g})$ activity in LNCaP cells in $60 \mathrm{~mm}$ dishes. pcDNA3 empty vector was used as the filler. (c) CMV-HA-E2F1 $(1.0 \mu \mathrm{g}), \mathrm{CMV}-\mathrm{E} 2 \mathrm{~F} 1_{\mathrm{E} 132}$ (which is a DNA binding-deficient E2F1 expression vector; $1.0 \mu \mathrm{g}$ ), or CMV-E2F1 $1_{1-284}$ (which is a transactivation-deficient $\mathrm{E} 2 \mathrm{~F} 1 \mathrm{expression}$ vector; $1.0 \mu \mathrm{g}$ ) were transiently cotransfected with BIN1-Luc $(1.0 \mu \mathrm{g})$ in LNCaP cells in $60 \mathrm{~mm}$ dishes. (d) Positive effect of forced expression of E2F1 on BIN1 promoter activity in a broad range of mammalian cell lines. (-); pcDNA3 alone, (+); CMV-HA-E2F1. (e) Effect of the E2F family of transcription factors (which includes the E2F1, E2F2, and E2F3a transactivators and the E2F4 transrepressor) on BIN1-Luc in LNCaP cells. All raw values of luciferase activity were obtained $24 \mathrm{~h}$ posttransfection and were normalized to cotransfected CMV- $\beta$-galactosidase $(0.2 \mu \mathrm{g})$. At least three independent transfections were performed and data presented are mean \pm standard error

$\left(\mathrm{CMV}-\mathrm{E} 2 \mathrm{~F} 1_{1-284}\right)$ failed to enhance BIN1 promoter activity (Figure 3c). BIN1-Luc activity was enhanced constantly by E2F1 transfection in various cell lines, which included the PC-3 prostate cancer line, the SAOS-2 osteosarcoma line, the MCF-7 breast cancer line, mouse embryonic fibroblasts (MEFs; Figure 3d), and the IMR90 human lung fibroblast line (data not shown), suggesting that E2F1-dependent BIN1 induction is not a cell line- or a tissue-specific event.

The E2F family of transcription factors includes both transcriptional activators, which include E2F1, E2F2, and E2F3a, and transcriptional repressors, which include E2F4 and E2F5. ${ }^{23}$ Similar to the apoptotic property of E2F1, ${ }^{5-9}$ forced expression of E2F2 and E2F3a induce apoptosis in vitro and in vivo. ${ }^{23}$ To determine whether all proapoptotic E2Fs (E2F1, E2F2, and E2F3a) activate the BIN1 promoter, each E2F expression vector was cotransfected with BIN1-Luc in LNCaP cells. E2F1, E2F2, and E2F3a consistently upregulated the BIN1 promoter, whereas the transrepressor E2F4 did not (Figure 3e): thus, it appears that the BIN1 promoter was commonly activated by all three proapoptotic E2F transactivators. We concluded that E2F1 is sufficient to enhance BIN1 promoter activity.

E2F1 was required for sustaining basal BIN1 expression. We next determined whether endogenous E2F1 sustains the basal levels of BIN1. To do this, LNCaP cells, which express functional E2F1 and BIN1 proteins, ${ }^{21}$ were transiently transfected with E2F1 siRNA. To monitor the effect of E2F1 siRNA on BIN1 promoter activity, BIN1-Luc was cotransfected. As a positive control for E2F1 activity, we 
a

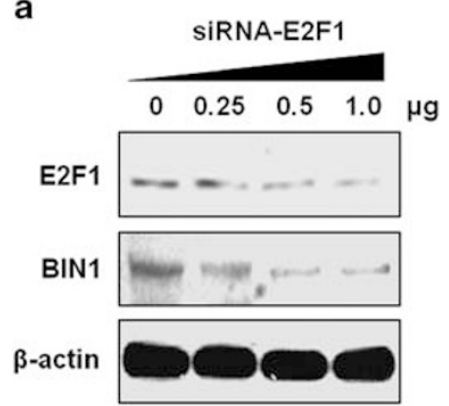

b

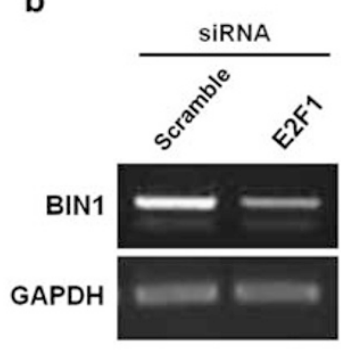

C

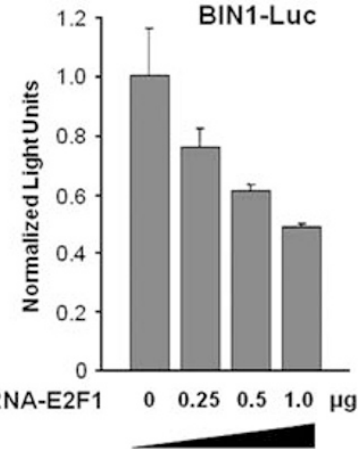

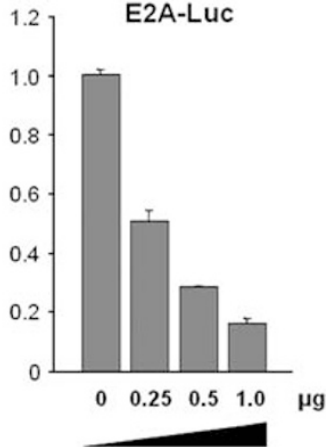

Figure 4 E2F1 was necessary to activate the BIN1 promoter. (a) Western blot analysis of endogenous E2F1 and BIN1 proteins in LNCaP cells. Cells were transfected with increasing doses of E2F1 siRNA (0-1.0 $\mu \mathrm{g})$. Scramble siRNA was included as the filler. $\beta$-Actin was used as the internal loading control. (b) The endogenous level of BIN1 mRNA expression was determined by RT-PCR in the presence or absence of E2F1 siRNA (1.0 $\mu \mathrm{g})$. Scramble siRNA (1.0 $\mu \mathrm{g})$ was used as a negative control. Endogenous GAPDH mRNA was used as the internal loading control. (c) Normalized luciferase light units of BIN1-Luc or E2A-Luc reporters in LNCaP cells with increasing doses of cotransfection of E2F1 siRNA. Scramble siRNA was included as the filler. Three independent transfections were performed and data presented are mean \pm standard error

a

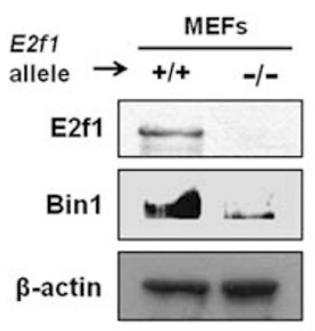

b

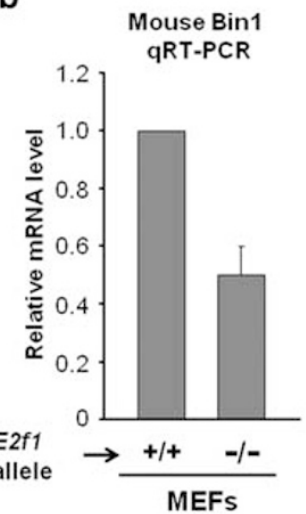

C

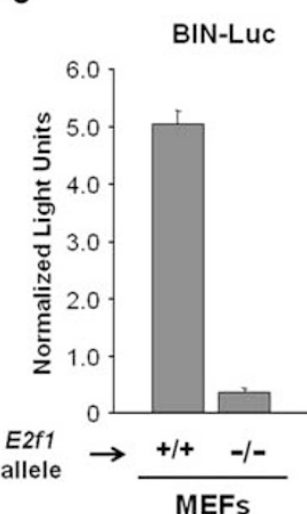

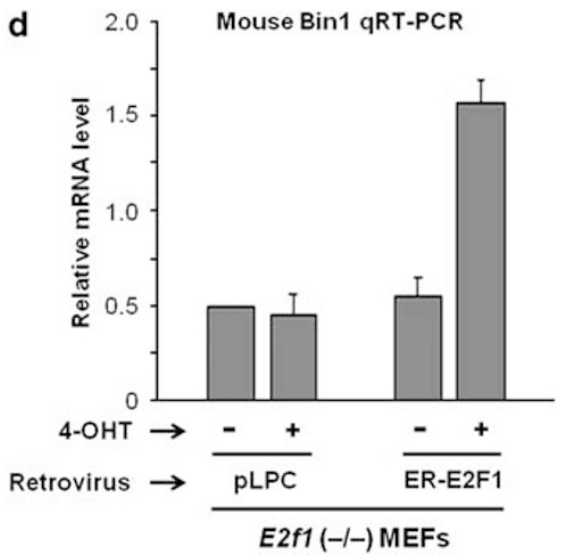

Figure 5 Bin1 deficiencies in E2f1 (-/-) MEFs were recovered only when E2F1 was ectopically restored. (a) Western blot analysis of endogenous E2f1 and Bin1 in wildtype (wt) MEFs (+/+) and E2f1-knockout MEFs (-/-). (b) Quantitative real-time RT-PCR (qRT-PCR) analysis of endogenous mouse Bin1 mRNA expressed in wt-MEFs and E2f1-knockout (-l-) MEFs. Endogenous mouse GAPDH mRNA was employed as the internal control. (c) Normalized luciferase light units of BIN1-Luc in wt (+/+) MEFs and E2f1 (-I-) MEFs. (d) The levels of endogenous Bin1 mRNA were determined by qRT-PCR in the presence or absence of $60 \mathrm{nM} 4-\mathrm{OHT}$ in the E2f1 (-/-) MEFs constitutively expressing recombinant ER-fusion E2F1 protein (see Supplementary Figure S1). Three independent qRT-PCR experiments were performed, and data presented are mean \pm standard error

used an adenovirus E2A promoter-driven luciferase reporter vector, E2A-Luc, which is directly activated by E2F1. ${ }^{21}$ The levels of endogenous E2F1 and BIN1 were decreased with increasing doses of E2F1 siRNA (Figure 4a). Concurrently, BIN1 mRNA expression was suppressed by E2F1 siRNA (Figure 4b). Moreover, the activities of the BIN1-Luc and E2A-Luc promoters were downregulated by cotransfection of E2F1 siRNA, with similar kinetics (Figure 4c). We concluded that basal BIN1 expression requires endogenous E2F1 activity.

BIN1 deficiency was rescued by ectopically expressed E2F1. BIN1 is a powerful repressor of oncogenic C-MYC. ${ }^{10-14,21}$ Therefore, we wondered if BIN1 deficiency due to E2F1 inactivation (see Figure 4) could be rescued gradually by an E2F1-like molecule, such as E2F2 or E2F3a (see Figure $3 e$ ) to retard spontaneous cell transformation caused by deregulated c-MYC. There are a number of potential transcription factors including $\mathrm{MyoD}^{20}$ that could upregulate BIN1 expression in the absence of E2F1 (see Supplementary Table S1). However, these possibilities were clearly eliminated because, in E2f1-knockout (-/-) MEFs, the levels of endogenous Bin1 protein (Figure $5 \mathrm{a}$ ), endogenous Bin1 mRNA (Figure 5b), and BIN1-Luc activity (Figure 5c) were consistently downregulated, which implies that E2F1 is a primary regulator of BIN1 gene expression.

To confirm this theory further, we asked if Bin1 deficiency in E2f1-knockout (-/-) MEFs is rescued after functional restoration of E2F1. To do this, E2f1 (-/-) MEFs were stably infected with an E2F1-inducible recombinant retrovirus, named pLPC-HA-ER-E2F1. Expression of the HA-tagged estrogen receptor (ER)-E2F1 fusion protein was confirmed by western blot analysis using an anti-HA antibody (Supplementary Figure S1-a). Incubation with 4-hydroxy tamoxifen (4-OHT), which is an estrogen derivative, at $60 \mathrm{nM}$ for $24 \mathrm{~h}$ led to the observations that (1) BIN1-Luc was effectively activated (Supplementary Figure S1-b), (2) the S phase population in the cell cycle was increased with little or no cell death in 
optimized culture conditions (Supplementary Figure S1-C), and (3) apoptotic cell death was morphologically confirmed in serum-deprived medium (Supplementary Figure S1-d). These observations suggest that HA-ER-E2F1 is functional in the presence of 4-OHT in E2f1 (-/-) MEFs. In this cell system, qRT-PCR assays confirmed that endogenous Bin1 mRNA levels were completely recovered on the addition of 4-OHT (Figure 5d). Collectively, we concluded that E2F1 is necessary and sufficient for activating BIN1 expression.

DNA damage failed to activate BIN1 expression unless endogenous E2F1 was intact. Various DNA-damaging agents consistently upregulated BIN1 levels (see Figure 1). Although DNA damage activates a number of cellular pathways that regulate cell-cycle progression, apoptosis, and DNA repair, transient transfection experiments using E2F1 siRNA in the presence of etoposide confirmed the essential role of E2F1 in BIN1 gene induction. Specifically, etoposidedependent induction of endogenous BIN1 expression was largely abolished by cotransfection of E2F1 siRNA in SAOS2 (Figure 6a) and LNCaP cells (Figure 6b). Similarly, the BIN1Luc promoter activity was not upregulated by etoposide in E2f1 (-/-) MEFs (Figure 6c). These data suggest that E2F1 is mostly responsible for the induction of BIN1 expression after DNA damage.

E2F1 directly bound the BIN1 promoter in response to DNA damage in vivo. To further characterize the mechanism by which E2F1 activates the BIN1 promoter, additional BIN1-luciferase reporters, denoted $-565 /+112-$ Luc, -319/+112-Luc, -285/+112-Luc, -178/+112-Luc, and $\Delta($ Sacll)/+112-Luc, were generated (Figure 7a). The $-565 /$ +112 -Luc vector does not contain the $\mathrm{E} 2 \mathrm{~F}(\alpha)$ consensus site, but includes both $\operatorname{E2} F(\beta)$ and $\operatorname{E} 2 \mathrm{~F}(\gamma / \delta)$ sites. The $-319 /$ +112 -Luc construct does not contain the $\operatorname{E2F}(\alpha)$ and $\operatorname{E2F}(\beta)$ sites, but retains the $\operatorname{E} 2 \mathrm{~F}(\gamma / \delta)$ sites. Although both the $-285 /$
+112 -Luc and the -178/+112-Luc constructs do not contain any of the four E2F recognition sites, the $5^{\prime}$ terminus of the $-285 /+112$-Luc promoter starts from the nucleotide that is immediately adjacent to the $\operatorname{E} 2 \mathrm{~F}(\gamma / \delta)$ site. The $\Delta($ Sacll $) /$ +112 -Luc construct contains both $\operatorname{E2F}(\alpha)$ and $\operatorname{E} 2 \mathrm{~F}(\beta)$, but not $\mathrm{E} 2 \mathrm{~F}(\gamma / \delta)$. Transient transfection of CMV-HA-E2F1 with each of these BIN1-promoter luciferase reporter vectors in LNCaP cells revealed that, although all putative E2F-binding sites contributed to the BIN1 promoter activity to some extent, the $-319 /-178$ region spanning $\operatorname{E} 2 \mathrm{~F}(\gamma / \delta)$ was most significantly involved in E2F1-induced activation of BIN1 promoter (Figure 7b).

To determine whether the $-319 /+112$-promoter activity is upregulated by endogenous E2F1 in response to DNA damage, the $-319 /+112$-Luc reporter vector was cotransfected with E2F1 siRNA with increasing doses of etoposide in LNCaP and SAOS2 cells. As predicted, the -319/+112-Luc activity was enhanced with etoposide, which was constantly reversed by cotransfection of E2F1 siRNA (Figure 7c). Although the BIN1-Luc (or -774/+112-Luc) activity was also upregulated with increasing doses of etoposide in LNCaP cells (see Figure 1c), the $-319 /+112$ BIN1 promoter was more readily activated by etoposide (Figure $7 \mathrm{c}$ ), suggesting that there is another cis-element within the $-774 /-319$ region that negatively modulates etoposide-induced BIN1 promoter activity. As the $-178 /+112$-Luc promoter was not activated by the overexpression of E2F1 (see Figure 7b), we hypothesized that activation of endogenous BIN1 promoter by E2F1 after DNA damage is largely mediated by the direct interaction between E2F1 protein and the $-319 /-178$ promoter region.

A chromatin immunoprecipitation (ChIP) assay was performed to test this hypothesis. We specifically amplified the $-320 /-158$ region of the human BIN1 promoter, which is almost identical to the $-319 /-178$ region (Figure $7 a$ ). Endogenous E2F1 protein was identified on the $-320 /-158$ a

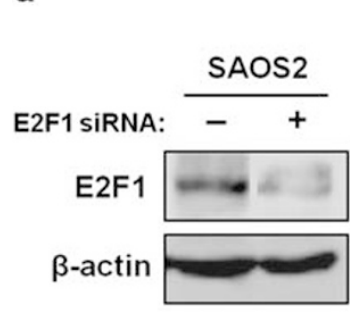

b

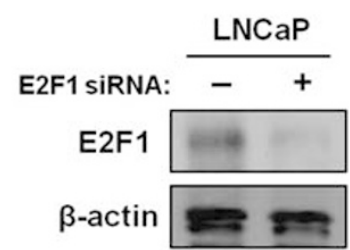

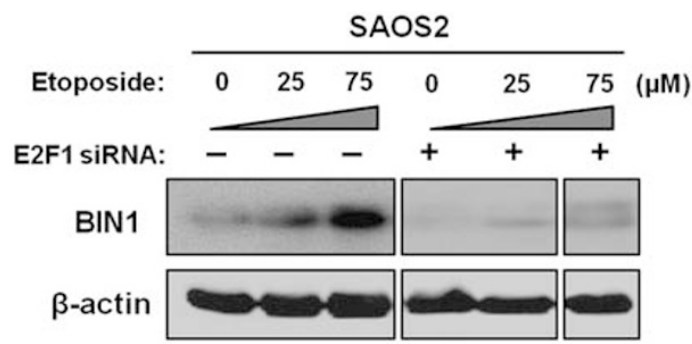

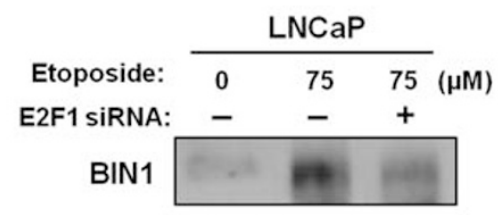

$\beta$-actin

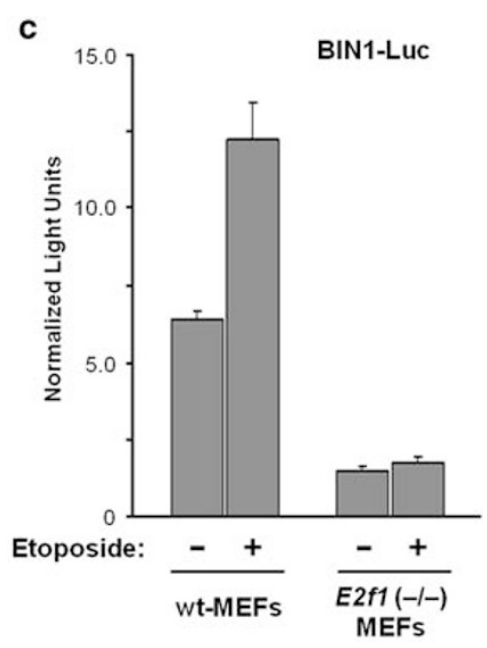

Figure 6 DNA damage upregulated BIN1 levels in an E2F1-dependent manner. Western blot analysis of endogenous E2F1 and BIN1 proteins in (a) SAOS2 and (b) LNCaP cells. Approximately $24 \mathrm{~h}$ after transfection of $1.0 \mu \mathrm{g}$ of scramble siRNA ( - ) or E2F1 siRNA $(+)$, cells were incubated in the presence or absence of etoposide for $24 \mathrm{~h}$. $\beta$-Actin was used as the internal loading control. (c) Wild-type (wt) $(+/+)$ and E2f1-knockout $(-/-)$ MEFs were transfected with BIN1-Luc (0.5 $\mu \mathrm{g})$. At approximately $24 \mathrm{~h}$ posttransfection, cells were incubated in the presence or absence of etoposide $(100 \mu \mathrm{M})$ for $24 \mathrm{~h}$. There was little or no morphological cell damage observed under these culture conditions (data not shown). Luciferase assays were performed independently three times, and data presented are mean \pm standard error 
a $\begin{array}{llll}-576 & -515 & -295 & -284\end{array}$ $E 2 F(\alpha) E 2 F(\beta) E 2 F(\gamma) E 2 F(\delta)$

Luciferase

b

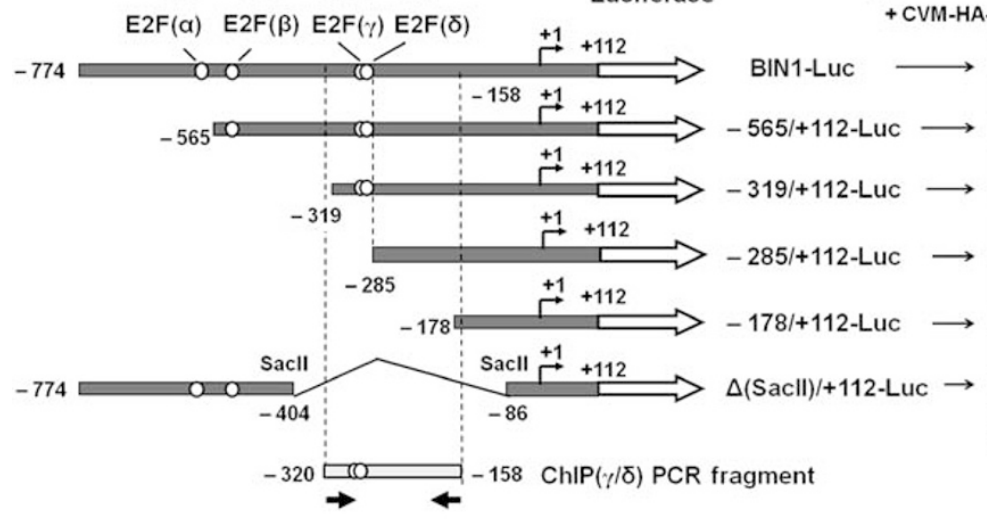
+ CVM-HA-E2F1

Relative Luciferase Activity

C
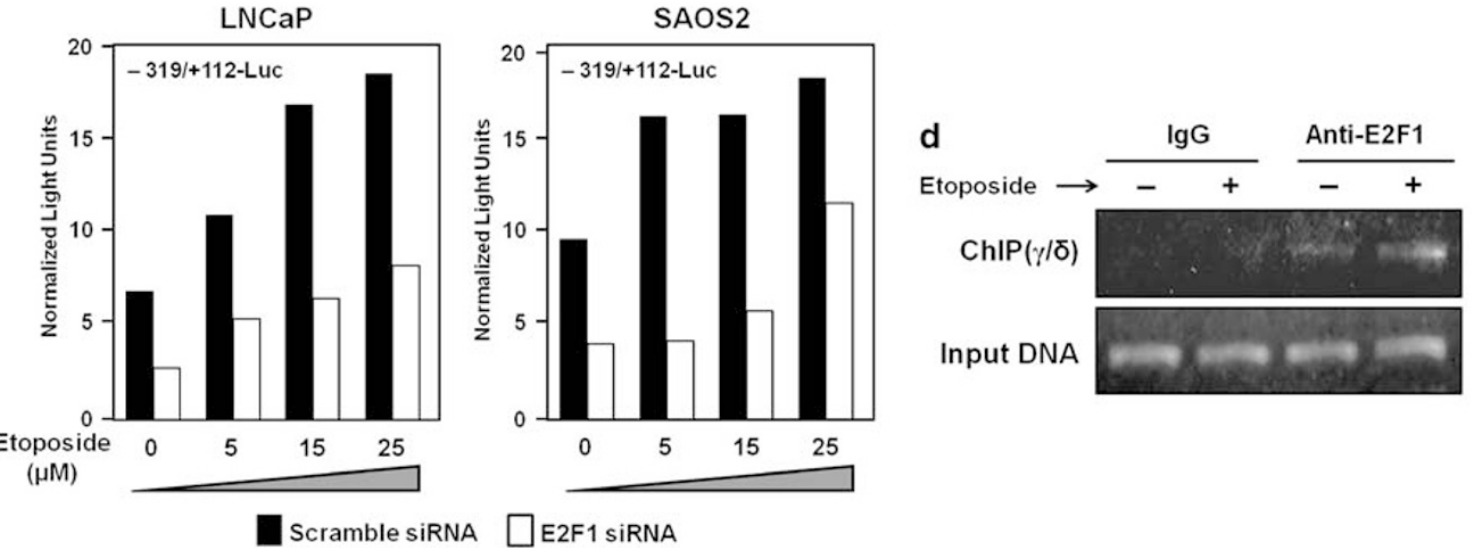

Figure 7 E2F1 directly upregulated BIN1 promoter activity. (a) Schematic illustration of a series of BIN1 promoter deletion mutants in the pGL2-Basic luciferase reporter and a ChIP-PCR fragment ChIP $(\gamma / \delta)$. Open circles denote the four putative E2F binding sites. The $-320 /-158$ region harboring the E2F $(\gamma / \delta)$ sites was amplified by ChIP analysis. Bold arrows indicate forward and reverse specific ChIP $(\gamma / \delta)$ primers. (b) Normalized luciferase light units of LNCaP cells transiently cotransfected with CMV-HAE2F1 $(1.0 \mu \mathrm{g})$ and the indicated deleted BIN1 promoter reporters $(0.5 \mu \mathrm{g})$. Three independent transfections were performed, and data presented are mean \pm standard error. (c) The $-319 /+112-L u c$ vector $(0.5 \mu \mathrm{g})$ was cotransfected with $1.0 \mu \mathrm{g}$ of either scramble siRNA (closed bars) or E2F1 siRNA (open bars) in LNCaP and SOAS2 cells. At approximately $24 \mathrm{~h}$ posttransfection, cells were incubated with increasing doses of etoposide $(0-25 \mu \mathrm{M})$ for an additional $24 \mathrm{~h}$. Luciferase assays were performed independently three times, and data presented are mean \pm standard error. (d) LNCaP cells were incubated in the presence $(+)$ or absence $(-)$ of etoposide for $24 \mathrm{~h}$ and were then harvested for ChIP analysis using an anti-E2F1 antibody or preimmune IgG. Specific primers were used to amplify the $-320 /-158$ region of the BIN1 promoter. Input chromatin was diluted to $1: 1000$. All PCR products were resolved by $2 \%$ agarose electrophoresis

promoter region in vivo, particularly after treatment with etoposide (Figure 7d). Transient transfection of an HA-E2F1 expression vector and subsequent anti-HA-ChIP analysis also revealed enhanced interactions between HA-E2F1 protein and BIN1 promoter even without DNA damage (data not shown). Thus, the increased levels of E2F1 protein per se, rather than DNA damage-induced chemical modification of E2F1 protein, may be critical for physical interactions between E2F1 protein and BIN1 promoter after DNA damage. We concluded that endogenous E2F1 interacts directly with the BIN1 promoter in vivo.

BIN1 was essential for E2F1-mediated cell death independently of p53 and p73. To determine whether BIN1 is essential for E2F1-induced cell death, we employed a BIN1-deficient cell system using the LNCaP cell line, LNCaP/AS-BIN1, which constitutively expresses antisense (AS) BIN1 cDNA. ${ }^{21}$ Endogenous BIN1 levels were substantially downregulated in AS-BIN1-expressing LNCaP cells, in which the maintenance of the stability of the transfected
E2F1 protein was confirmed (Figure 8a). Using this model system, we determined (1) whether forced expression of E2F1 suppresses cancer cell proliferation in optimized culture conditions, (2) whether E2F1-induced growth arrest is attributable to apoptosis, and (3) whether BIN1 is required for E2F1-induced apoptosis. To do this, we performed two cell-based assays: (1) colony formation assay, which evaluates overall clonogenic growth/survival rates (regardless of the mechanism) and (2) chromatin condensation assay, which assesses apoptotic cell death. We observed that E2F1-induced colony suppression (Figure 8b) was attributed to apoptotic cell death (Figure $8 \mathrm{c}$ ), which was constantly abolished by AS-BIN1 (Figures $8 \mathrm{~b}$ and $\mathrm{c}$ ). These results suggest that endogenous BIN1 expression is essential for the growth arrest due to apoptosis induced by E2F1.

In response to DNA damage, E2F1 stabilizes the p53 tumor suppressor via a p14 ${ }^{\mathrm{ARF}}$-dependent mechanism, whereas it also transcriptionally induces the $p 73$ gene expression. ${ }^{5-7}$ Therefore, we hypothesized that BIN1 collaborates with p53 or p73 to sensitize cancer cells to DNA-damaging agents. 
a

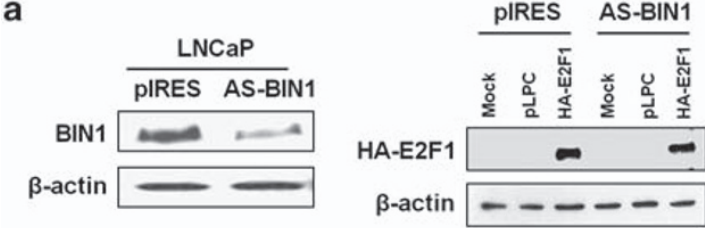

b

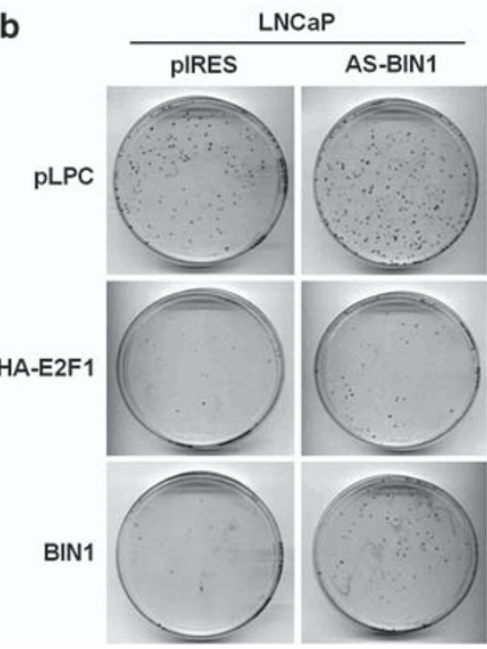

C
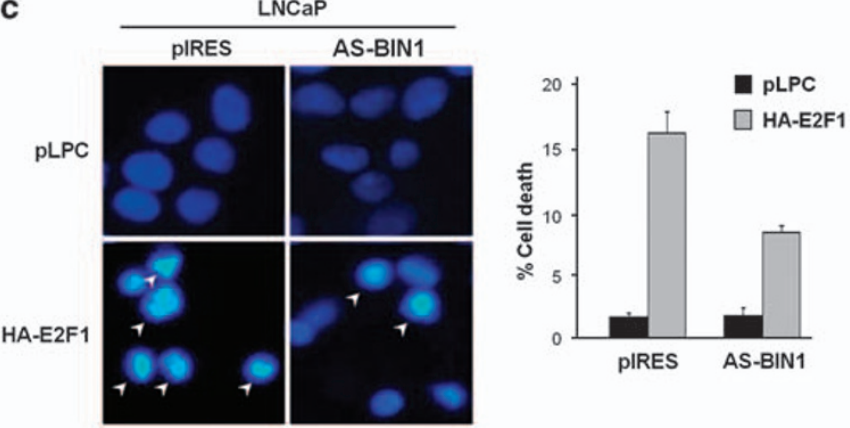

LNCaP/pIRES

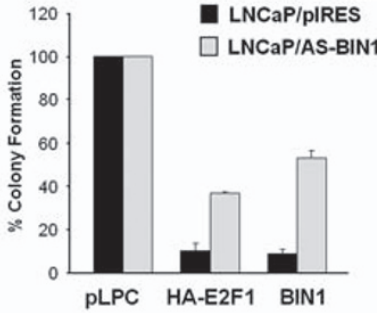

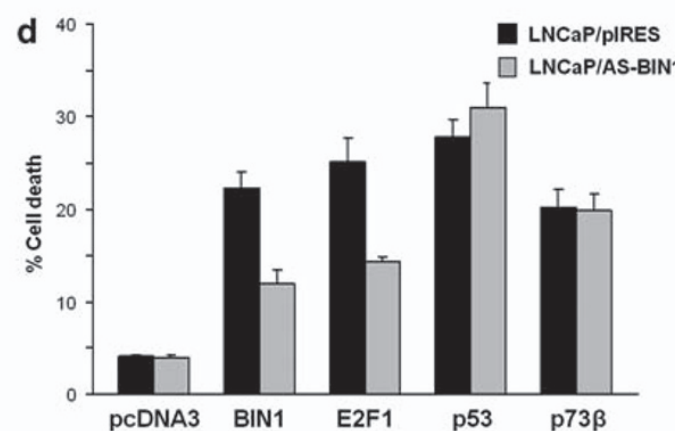

Figure 8 BIN1 was essential for the apoptosis mediated by E2F1, but not by p53 and p73. (a) Western blot analysis of LNCaP/pIRES and LNCaP/AS-BIN1 cell lysates probed with an anti-BIN1 antibody (2F11). Stable expression of pIRES-AS-BIN1 (neo) was achieved using high doses of G418 (1000 $\mu \mathrm{g} / \mathrm{ml}$ ) in growth medium (left panel). $\mathrm{LNCaP} / \mathrm{pIRES}$ and LNCaP/AS-BIN1 cells were transiently transfected with $2.0 \mu \mathrm{g}$ of pLPC empty vector or pLPC-HA-E2F1 for $48 \mathrm{~h}$. Precleared lysates were subjected to western blot analysis with an anti-HA antibody (right panel). $\beta$-Actin was used as the internal loading control. (b) Colony formation assay. LNCaP/pIRES and LNCaP/AS-BIN1 cells were seeded at the density of $1 \times 10^{5}$ cells per $60 \mathrm{~mm}$ dish for transfection with $2.0 \mu \mathrm{g}$ of pLPC (puromycin-resistant) empty vector, pLPC-HA-E2F1, or pLPC-BIN1. At approximately $24 \mathrm{~h}$ after transfection, cells were cultured in the presence of puromycin $(0.45 \mu \mathrm{g} / \mathrm{ml}$ ) for 2 weeks. Drug-resistant colonies were stained with $0.04 \%$ (w/v) Giemsa solution (left panel) to score clonogenic growth/survival efficiency by comparison with the control vector. CMV- $\beta$-galactosidase $(0.2 \mu \mathrm{g})$ was cotransfected as an internal control to confirm (or normalize) the transfection efficiency (data not shown). Three independent colony formation assays were performed and data presented are mean \pm standard error (right panel). (c) Apoptosis assay. Both floating and adherent cells were harvested in PBS, fixed in formaldehyde, and subjected to DAPI staining to detect chromatin condensation. White arrowheads indicate condensed chromatin, which is an index of apoptotic cell death (left panel). Three independent DAPI staining assays were performed and data presented are mean \pm standard error (right panel). (d) Cells were transfected with $2.0 \mu \mathrm{g}$ of each stipulated expression vector and then incubated for 48-72 h. Both floating and adherent cells were harvested in PBS and were subjected to the DAPI staining assay. Three independent experiments were performed and data presented are mean \pm standard errors

To test this hypothesis, the LNCaP/AS-BIN1 cells were transfected with the CMV-p53 and CMV-p73 $\beta$ expression vectors individually. CMV-BIN1 and CMV-E2F1 vectors were transfected separately as positive controls. We found that AS-BIN1 did not decrease the apoptosis mediated by p53 and p73, whereas, as predicted, it inhibited the apoptosis induced by E2F1 and BIN1 (Figure 8d). We concluded that BIN1 mediates E2F1-induced apoptosis in a manner that is independent of (or parallel to) p53 and p73.

BIN1 was essential for cancer cell death after DNA damage. DNA damage stabilizes E2F1 with subsequent induction of apoptosis. ${ }^{5-7,15}$ In this study, we found that DNA damage increased BIN1 levels when endogenous E2F1 was intact (see Figure 6). In view of that, we hypothesized that BIN1 is a critical effector for E2F1 to induce cell death after DNA damage. To test this hypothesis, the LNCaP/AS-BIN1 cell line was treated with etoposide for $24 \mathrm{~h}$. Chromatin condensation (Figure 9a) and Annexin V binding apoptosis assays (Figure 9b) consistently demonstrated that depletion of endogenous BIN1 rendered LNCaP cells resistant to DNA damage-induced cell death. There was little or no negative impact of AS-BIN1 on the levels of endogenous E2F1 induction following DNA damage (data not shown). We concluded that BIN1 is required for the DNA damageinduced apoptosis mediated by E2F1.

BIN1 did not require caspase activity for mediating cell death after DNA damage. In response to genotoxic stress, E2F1 transcriptionally activates a variety of caspaserelated proapoptotic genes, including the $\mathrm{BH} 3$-only proteins, Apaf-1, and caspase itself. ${ }^{5-7}$ Subsequently, E2F1 promotes caspase-dependent apoptosis. ${ }^{5-7}$ However, the precise mechanism by which E2F1 enhances caspase-independent cell death is largely unknown. Interestingly, Elliott et al. ${ }^{14}$ demonstrated that overexpressed BIN1 did not activate caspases and that BIN1-induced cell death was not blocked by a polycaspase inhibitor Z-VAD-fmk. Thus, the 'E2F1-BIN1' axis (this study) may provide E2F1 with a caspase-independent death property. To confirm this possibility, we determined whether AS-BIN1 alters endogenous caspase activity after DNA damage. To do this, proteolytic cleavage of poly(ADP-ribose) polymerase-1 (PARP-1), which is a substrate of caspase-3, and procaspase-3, which is a substrate of the apoptosome, was analyzed in the presence of etoposide. Staurosporine was 
a

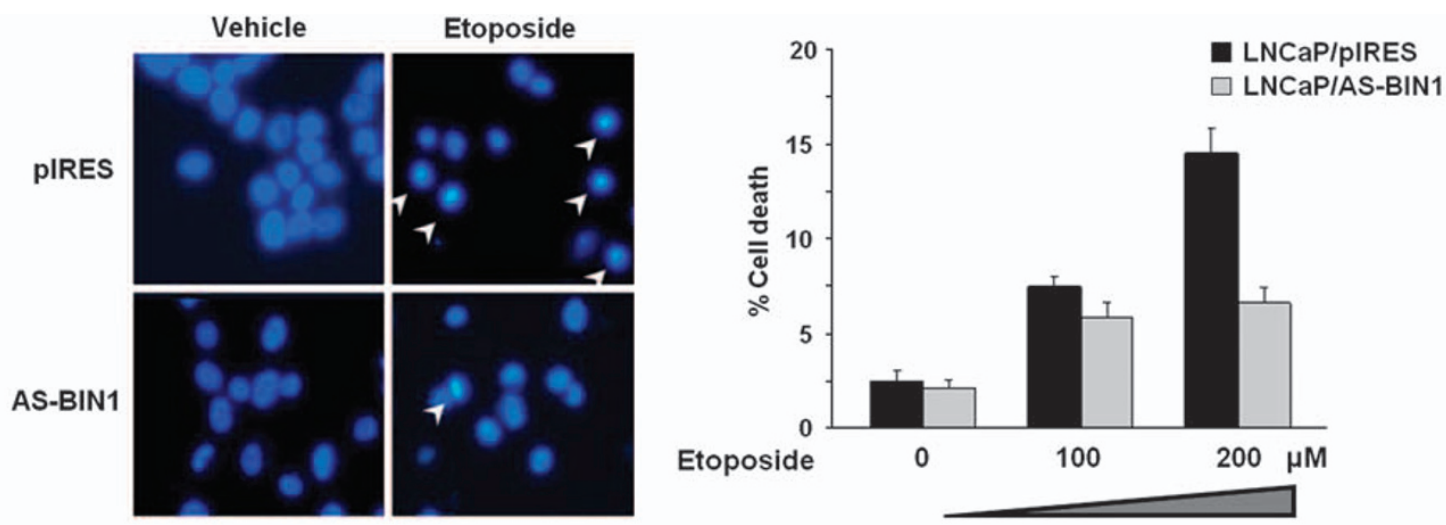

b

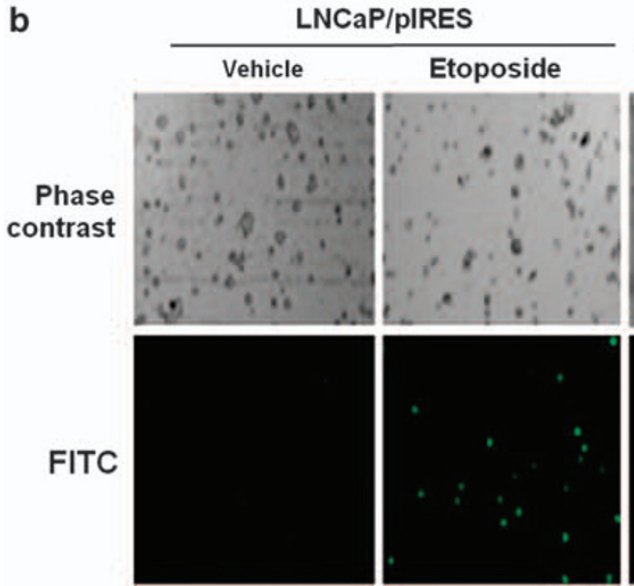

NCaP/pIRES

LNCaPIAS-BIN1
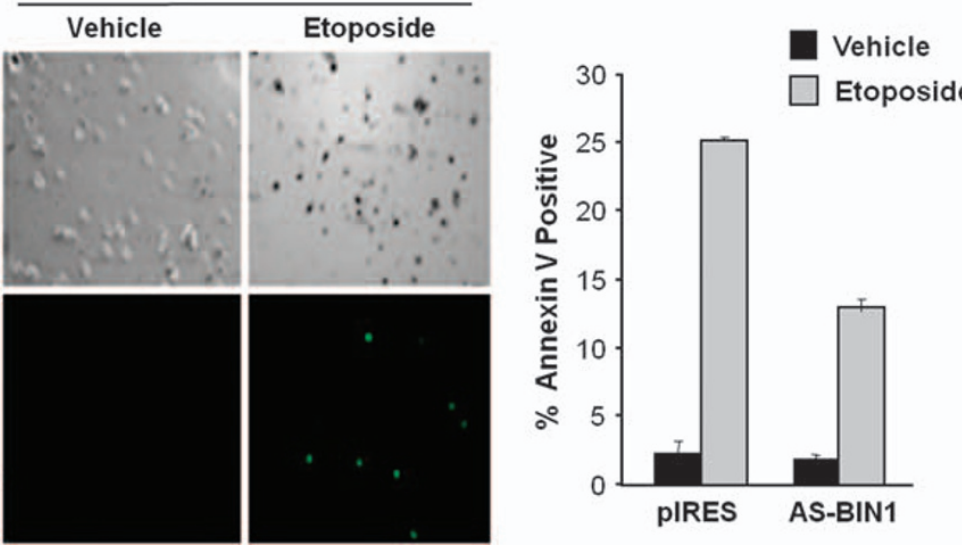

Figure 9 BIN1 was necessary to increase cancer sensitivity to cell death following DNA damage. (a) LNCaP/pIRES and LNCaP/AS-BIN1 cells were treated with increasing doses of etoposide for $24 \mathrm{~h}$ and were then harvested in PBS, fixed in formaldehyde, and subjected to DAPI staining. White arrowheads indicate condensed chromatin, an index of apoptotic cell death (left panel). Three independent experiments were performed and data presented are mean \pm standard error (right panel). (b) Cells were treated with etoposide for $24 \mathrm{~h}$ and were then harvested in ice-cold PBS and subjected to Annexin V staining. Annexin V-positive cells (apoptotic cells) were detected as green spots by fluorescence microscopy using an FITC filter (left panel). Three independent datasets are presented as mean \pm standard error (right panel)

a

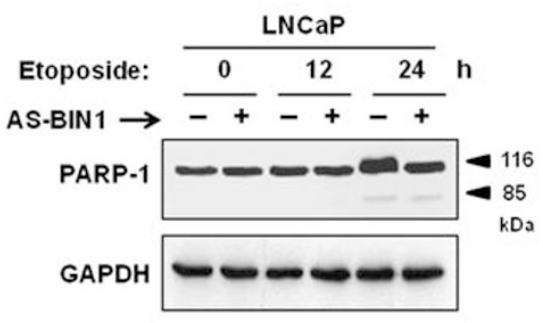

b

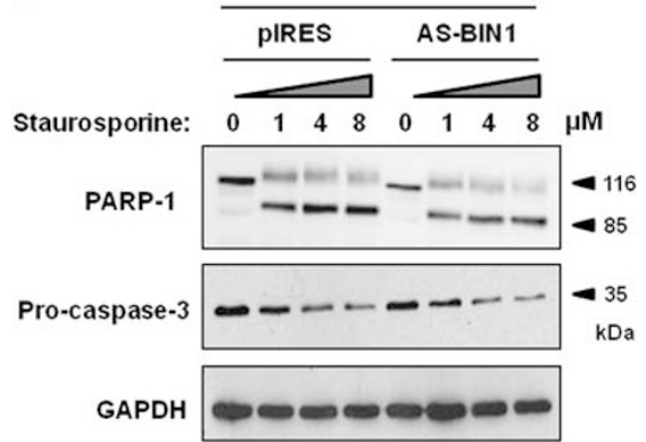

Figure 10 BIN1 did not activate caspases to sensitize cancer cells to DNA damage. LNCaP/pIRES and LNCaP/AS-BIN1 cells were treated with (a) etoposide or (b) staurosporine. Precleared cell lysates were subjected to western blot analysis. Blots were probed with an anti-PARP-1 antibody or an anti-pro-caspase-3 antibody. GAPDH was used as the internal loading control

used as a positive control for the stimulation of endogenous caspase activity.

Etoposide-induced cell death, which was consistently blocked by AS-BIN1 (see Figure 9), was not accompanied by PARP-1 cleavage in LNCaP cells (Figure 10a). The failure of PARP-1 cleavage after DNA damage was not attributable to either caspase-resistant PARP-1 or dysfunctional caspase-3 in this cell line, as staurosporine evidently induced the cleavage of PARP-1 and pro-caspase-3 (Figure 10b). Moreover, staurosporine was able to induce apoptosis regardless 
of AS-BIN1 (data not shown). These data suggest that etoposide-induced cancer cell death largely depends on BIN1 levels, rather than caspase activity and, conversely, that depletion of BIN1 does not compromise intrinsic caspase activity. We concluded that the proactive role of BIN1 in cell death after DNA damage does not require caspase activity.

\section{Discussion}

In this study, we found that BIN1, originally identified as a C-MYC-interacting proapoptotic tumor suppressor, is a novel transcriptional target of E2F1 (Figures 1-3). We present evidence that E2F1 is necessary and sufficient for the activation of the human BIN1 promoter (Figures 4 and 5), particularly after DNA damage (Figures 6 and 7). Moreover, endogenous BIN1 ablation significantly compromises cellular sensitivity to the apoptosis mediated by E2F1 and etoposide, but not by p53, p73 (Figures 8 and 9) or caspases (Figure 10). Therefore, the 'E2F1-BIN1' axis represents a novel pathway through which DNA damage-induced cell death is activated in cancer cells, regardless of p53, p73, and caspases (Figure 11).

Our findings may also shed light on the crosstalk between E2F1 and c-MYC in DNA-damage-induced apoptosis. E2F1 and $\mathrm{C}-\mathrm{MYC}$ are major transcription factors involved in cellcycle promotion. However, under certain conditions, these transcription factors induce apoptosis via p53-dependent and p53-independent mechanisms. ${ }^{25,26}$ Of note, the proapoptotic activity of c-MYC is largely abolished in E2f1 (-/-) MEFs, ${ }^{27}$ which suggests that E2F1 activity is a vital element in c-MYCdependent apoptosis. Although p14/p19 ARF is induced by E2F1 and enhances C-MYC-induced apoptosis, ${ }^{28}$ the mechanism by which E2F1 promotes the apoptosis mediated by

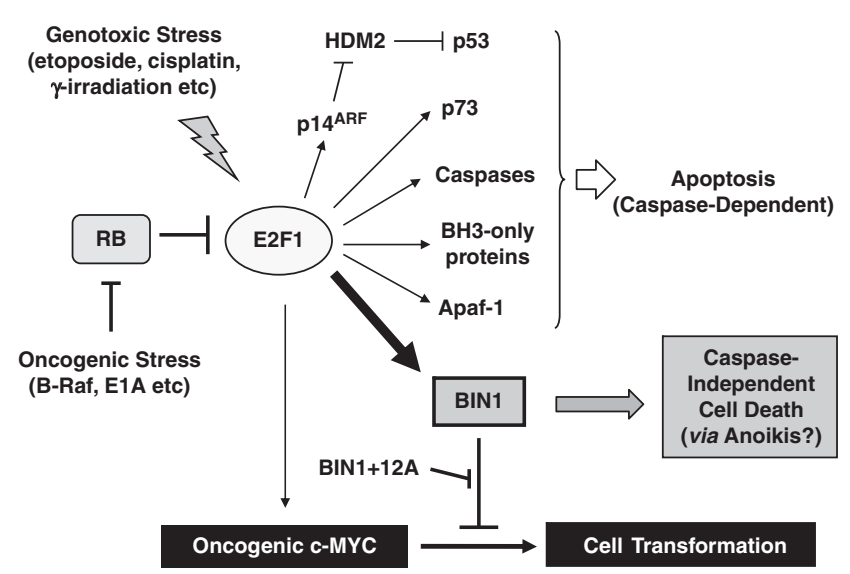

Figure 11 Role of BIN1 in E2F1-induced cell death in response to genotoxic and oncogenic stresses. The 'E2F1-BIN1' proapoptotic axis is independent of (or parallel to) the pathways mediated by $p 53$ or p73 leading to DNA damage-induced cell death. As BIN1 limits oncogenic properties of C-MYC via activating caspaseindependent cell death, ${ }^{12-14}$ E2F1-mediated BIN1 activation may be a potent mechanism for cancer suppression, particularly when RB is inactivated or C-MYC is deregulated. The 'E2F1-BIN1' axis may also shed light on the paradoxical role of $\mathrm{E} 1 \mathrm{~A}$ oncoprotein in anoikis. Identification of molecular mechanisms that disturb the 'E2F1-BIN1' axis caused by the deficiency (or dysfunction) of BIN1 (e.g., by a cancer-associated aberrant spliced isoform, BIN $1+12 A^{18,24}$ ) may unravel new genetic predisposition to cancer initiation and progression (see Discussion)
c-MYC via p14/p19ARF remains to be established. Based on the confirmed 'E2F1-BIN1' axis (this study), we suggest that the failure of c-MYC to induce apoptosis in E2f1 (-/-) MEFs can be attributed, at least partly, to the loss of endogenous Bin1 expression, possibly caused by E2f1 deficiency (Figure 5). As BIN1 is critical in limiting oncogenic c-MYC properties by mediating apoptosis ${ }^{13}$ or suppressing the cell cycle, ${ }^{21}$ we propose a novel proapoptotic interplay between E2F1 and C-MYC, in which E2F1 curbs the oncogenic activity of C-MYC by enhancing the levels of its proapoptotic binding partner, BIN1 (Figure 11). The disruption of the 'E2F1-BIN1-C-MYC' axis may compose a potential mechanism by which deregulated c-MYC stimulates spontaneous tumor formation in E2f1-knockout mice. ${ }^{8,9}$

Notably, the human BIN1 gene was recently identified again via genome-wide siRNA screening as one of the cellular genes essential for the senescence and apoptosis induced by oncogenic B-RAF in human primary (polarized) cells. ${ }^{29} \mathrm{RB}$ can be inactivated by oncogenic RAF, which subsequently releases E2F1. ${ }^{4}$ Thus, the 'E2F1-BIN1' axis we report here may constitute a potent backup mechanism for RB, by which cells attenuate malignant transformation caused by dysfunctional RB. Similarly, adenovirus E1A oncoprotein inactivates $\mathrm{RB}$ to release E2F1, ${ }^{1,4}$ which then upregulates BIN1 expression in human carcinoma cells (Figure 2c). Hence, our study linking BIN1 to E2F1-mediated apoptosis may also offer a possible explanation of the paradoxical function of $E 1 A$ 'oncoprotein' as a 'tumor suppressor' in human carcinoma cells. ${ }^{30}$ Intriguingly, when E1A acts as a functional tumor suppressor in vitro, ${ }^{30}$ it enhances the repolarization (or reepithelialization) of cancer cells ${ }^{31}$ and sensitizes them to anoikis, a process of cell death specifically activated by the disturbance of epithelial cell-matrix interactions. ${ }^{32}$ In contrast, when normal (polarized) epithelial cells are oncogenically transformed, they lose their proper polarity signaling and acquire cell mobility and proliferation potential via the epithelial-to-mesenchymal transition (EMT), an essential process leading to neoplastic transformation. ${ }^{33}$ As a result, depolarized cells become cancerous and resistant to anoikis. $^{32,33}$ Although the C-terminal binding protein, CtBP, a universal transcriptional corepressor, is involved to some extent in E1A-mediated cell polarity and anoikis, ${ }^{34}$ it is not precisely clear how E2F1 contributes to E1A-mediated reepithelialization and, conversely, how deregulated cell polarity signaling results in the loss of anoikis during EMT.

In this context, the potential involvement of BIN1 in cell polarity signaling (and thereby anoikis) is worth mentioning. Recent studies of the BIN1 gene orthologues in different organisms, including budding yeast, ${ }^{35}$ fission yeast, ${ }^{36}$ and Drosophila, ${ }^{37}$ strongly suggest the functional relevance of BIN1-related (or BIN1-like) genes in the normal processes of cell polarity signaling and tissue remodeling. ${ }^{19}$ Moreover, prompted by accumulating evidence in mammalian cells, it is pertinent to investigate the role of BIN1 in E1A-mediated repolarization and anoikis, through which $\mathrm{E} 1 \mathrm{~A}$ may act as a tumor suppressor. This evidence includes (1) the p53independent anoikis induced by a farnesyl transferase inhibitor (FTI), ${ }^{38}$ (2) the involvement of BIN1 in FTI-mediated apoptosis, $^{39}$ (3) the induction of BIN1 expression by E1A in human carcinoma cells (Figure 2c), and (4) the cell polarity 
proteins commonly targeted by tumorigenic human viruses. ${ }^{40}$ We propose that the 'E2F1-BIN1' axis renders carcinoma cells sensitive to $\mathrm{E} 1 \mathrm{~A}$-induced anoikis, possibly by regulating proper cell polarity signaling (Figure 11).

The pivotal role of BIN1 as an authentic tumor suppressor protein in vivo, particularly during aging, has been established recently by the germline deletion of Bin1 in mice. ${ }^{19,41,42}$ Consistent with this finding, the rates of BIN1 deficiency reported in a variety of human cancer cell lines and cancer tissues are noteworthy. ${ }^{10,16,17}$ For example, BIN1 mRNA levels were reduced or undetectable in more than $50 \%(15 / 27)$ of human cancer cell lines derived from a variety of different organs. ${ }^{10}$ Immunohistochemical analysis verified that BIN1 protein was deficient in over $50 \%(14 / 26)$ of primary breast carcinoma tissues, but was consistently detected in nonmalignant breast epithelial tissues. ${ }^{16}$ Loss of heterozygosity at the human BIN1 locus was detected in approximately $40 \%$ $(6 / 15)$ of patients with prostate cancer. ${ }^{17}$ Moreover, BIN1 mRNA was undetectable in $50 \%(4 / 8)$ of primary prostate carcinomas and nearly $90 \%(8 / 9)$ of metastatic prostate tumors. ${ }^{17}$ These facts clearly suggest potential mechanisms involving the loss of BIN1 during carcinogenesis, possibly via EMT, even in the presence of deregulated E2F1.

In summary, we have presented evidence that BIN1 is a bona fide transcriptional target of E2F1 and is a critical mediator of E2F1-induced cell death in response to DNA damage. Our study also suggests a potential role of BIN1 in response to anti-RB oncogenic stresses. To explain the possible link between BIN1 and cell polarity signaling, ${ }^{19,30-33}$ we propose that BIN1 loss in the presence of E2F1, which is seen in many advanced human cancers, ${ }^{10,16,17}$ may be associated with the loss of anoikis. ${ }^{32,38,39}$ Further studies of BIN1 functions, such as the identification of a proapoptotic BIN1 effector and a role of BIN1 in cell polarity signaling, should provide new insights into the growth-arresting mechanisms mediated by E2F1 and BIN1. The 'E2F1-BIN1' axis offers a mechanistic basis for the cellular stress response and extends our understanding of the interaction and significance of these proapoptotic proteins in cancer suppression and normal tissue development.

\section{Materials and Methods}

Plasmid DNAs and siRNAs. The human full-length BIN1 CDNA expression vector, CMV-BIN1, the antisense (AS) BIN1 CDNA expression vector, pIRES-ASBIN1, the hemagglutinin (HA)-tagged human full-length E2F1 cDNA expression vector, CMV-HA-E2F1, the adenovirus E1A expression vector, p1Aneo, the adenovirus E2A gene promoter-driving luciferase vector, E2A-Luc, two E2F1 mutant expression vectors, $\mathrm{CMV}-\mathrm{E} 2 \mathrm{~F} 1_{\mathrm{E} 132}$ and $\mathrm{CMV}-\mathrm{E} 2 \mathrm{~F}_{1-284}$, and the $\mathrm{E} 2 \mathrm{~F}$ family expression vectors, CMV-E2F2 and CMV-E2F3a, were described in an earlier report. ${ }^{21}$ CMV-p73 $\beta$ was a gift from Dr. G Melino. To construct pLPC-HA-ER-E2F1, which is an E2F1-inducible retroviral vector, a $2.3 \mathrm{~kb}$ EcoRI/Nott-digested cDNA fragment encoding an HA-tagged estrogen receptor (ER)-E2F1 fusion protein (a gift from Dr. K Helin) was subcloned into the pLPC (puromycin-resistant) vector.

The pGL2-Bgll luciferase reporter vector, ${ }^{20}$ named BIN1-Luc here, contains an 886 bp Bgll-digested DNA (-774/+112) fragment encompassing the human BIN1 gene promoter in the sense direction. Using a standard PCR technique, sequential deletions of the human BIN1 promoter from the $5^{\prime}$ end were performed to generate four truncated DNA fragments, designated $-565 /+112,-319 /+112,-285 /+112$, and $-178 /+112$. The nucleotide sequences of forward $P C R$ primers containing a Xhol subcloning site (underlined) were: $5^{\prime}$-ACACTCGAGAGGGCAAAGATGTGGAGATGT-3' (-565 forward), 5'-TTACTCGAGCCTGGGTTGCAGGAGAGTTA-3' (-319 forward), 5'-TATCTCGAGAAAGAACAAGACGCCAG-3' (-285 forward),

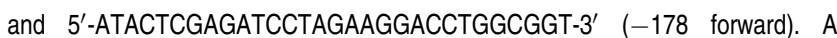
Hindlll site (italicized) was added to the common reverse primer, $5^{\prime}$-AGA AAGCTTACAGCGGAGCCAACTGAC- $3^{\prime}$ (+112 reverse). All PCR products were digested with Xhol and Hindlll and subcloned into pGL2-Basic (Promega, Madison, WI, USA) to generate the luciferase constructs $-565 /+112$-Luc, $-319 /+112$-Luc, -285/+112-Luc, and -178/+112-Luc. To create the $\Delta($ Sacll)/+112-Luc, which harbors a Sacll-Sacll deletion of the region between positions -404 and -86 , BIN1-Luc was digested with Sacll to remove the inner $318 \mathrm{bp} \mathrm{Sacll-Sacll} \mathrm{(-404/}$ -86) fragment, and the outside vector arm DNA $(6.1 \mathrm{~kb})$ was self-ligated. All plasmids were verified by restriction digestion and/or DNA sequencing.

For gene silencing of endogenous E2F1, RB, and BIN1, we used an E2F1 siRNA expression vector (GenEclipse-E2F1; Chemicon, Charlottesville, VA, USA), an RB siRNA expression vector (pKD-RB-v3; Millipore, Billerica, MA, USA), and a BIN1 siRNA (sc-29804; Santa Cruz Biotechnology, CA, USA), respectively. Scramble (control) siRNA (sc-37007) was used as the filler (or a negative control). For transfection of plasmid DNA and siRNA, the FuGENE 6 and $X$-tremeGENE reagents were used, respectively, according to the manufacturer's instructions (Roche Applied Science, Indianapolis, IN, USA).

Tissue culture. All commercially available cell lines used in this study were purchased from the American Type Culture Collection (ATCC, Manassas, VA, USA). Cells were maintained in $5 \% \mathrm{CO}_{2}$ at $37^{\circ} \mathrm{C}$. The $\mathrm{LNCaP}$ human prostate cancer cell line, the PC-3 human prostate cancer cell line, and the SAOS2 human osteosarcoma cell line were grown in RPMI 1640, Ham's F-12 Nutrient Mixture, and McCoy's 5A medium, respectively. Other cell lines and primary mouse embryonic fibroblasts (MEFs) used in this study were grown in Dulbecco's Modified Eagle's Medium (DMEM). All growth media were supplemented with $10 \%(\mathrm{v} / \mathrm{v})$ fetal bovine serum (FBS), $100 \mathrm{U} / \mathrm{ml}$ penicillin-G, $100 \mu \mathrm{g} / \mathrm{ml}$ streptomycin sulfate, and $2 \mathrm{mM}$ L-glutamine (Invitrogen, Carlsbad, CA, USA). MEFs (E2f1-l-) and wt-control MEFs $(+/+)$ were generously provided by Dr. L Yamasaki. Etoposide, adriamycin, and cisplatin (Sigma, St. Louis, MO, USA) were dissolved in dimethyl sulfoxide (DMSO) at concentrations of $50 \mathrm{mM}, 100 \mathrm{mM}$, and $200 \mu \mathrm{g} / \mathrm{ml}$, respectively. Cells were $\gamma$-irradiated in a collimator insert by using a JL Shepherd Mark I Model 30 Cesium Irradiator at $50 \mathrm{~Gy}$ single dose for $200 \mathrm{~s}$.

The LNCaP/AS-BIN1 cell line, which stably expresses antisense BIN1 (AS-BIN1) CDNA, was established recently by using the pIRES expression vector (Clontech, Mountain View, CA, USA). ${ }^{21}$ To generate an ER fusion HA-E2F1-inducible cell line using E2f1 (-I-) MEF cells, the pLPC-HA-ER-E2F1 plasmid was cotransfected with pVSV-G helper plasmid into a GP2-293 packaging cell line (Clontech). At approximately $48 \mathrm{~h}$ posttransfection, actively growing E2f1 (-I-) MEFs were overlaid with the culture supernatant of pLPC-HA-ER-E2F1-transfected GP2-293 cells, and were then selected for 2 weeks in DMEM supplemented with $10 \%(\mathrm{v} / \mathrm{v})$ charcoal-dextran-treated (CDT)-FBS (Hyclone, Logan, UT, USA) and $0.6 \mu \mathrm{g} / \mathrm{ml}$ of puromycin (Calbiochem, San Diego, CA, USA). Stable expression of HA-ER-E2F1 was confirmed by western blotting with an anti-HA (3F10) antibody. To facilitate nuclear translocation of the cytoplasmic HA-ER-E2F1 protein, 4-hydroxy tamoxifen (4-OHT; Sigma) was added to the medium (final concentration of $60 \mathrm{nM}$, which was determined via BIN1-Luc assays; see Supplementary Figure S1-b)

Western blotting. Cells were lysed in $\mathrm{BC} 200$ lysis buffer $(200 \mathrm{mM} \mathrm{NaCl}, 0.2 \%$ NP-40, 10\% (v/v) glycerol, $1.0 \mathrm{mM}$ dithiothreitol (DTT), $1.0 \mathrm{mM}$ EDTA, and $25 \mathrm{mM}$ Tris- $\mathrm{HCl}, \mathrm{pH} 7.8)$ containing $1 \%(\mathrm{v} / \mathrm{v})$ eukaryotic proteinase inhibitor cocktail (Calbiochem). Protein concentrations were determined using the Bradford reagent (Bio-Rad, Hercules, CA, USA). Precleared protein lysates were resolved by sodium dodecyl sulfate-polyacrylamide gel electrophoresis (SDS-PAGE), and transferred to a nitrocellulose membrane for $1 \mathrm{~h}$ at $100 \mathrm{~V}$ in Towbin buffer (192 $\mathrm{mM}$ glycine, $20 \%$ methanol, and $25 \mathrm{mM}$ Tris- $\mathrm{HCl}, \mathrm{pH}$ 8.3). Membranes were blocked using $5 \%$ non-fat skim milk in PBST (PBS containing $0.1 \%$ Tween 20 ) overnight at $4{ }^{\circ} \mathrm{C}$ with gentle rocking, followed by hybridization with the appropriate primary and secondary antibodies. The primary antibodies used were: BIN1 (clone 2F11, Sc-23918), E2F1 (sc-251), E2F2 (sc-22821), E2F3 (sc-879), E2F4 (sc-1082), PARP-1 (sc-7150; Santa Cruz Biotechnology), caspase-3 (no. 9665; Cell Signaling Technology, Danvers, MA, USA), and HA (3F10; Roche Applied Science). Bands were visualized using the SuperSignal West Pico Chemiluminescent substrate (Pierce, Rockford, IL, USA). Membranes were stripped with Western Blot Stripping Buffer (Pierce) for $15 \mathrm{~min}$ at room temperature (r.t.), and were reprobed with an anti- $\beta$-actin (A441; Sigma) antibody. 
Luciferase reporter assay. Cells seeded in $6 \mathrm{~cm}$ dishes were harvested in $500 \mu$ l luciferase lysis buffer ( $1 \%$ Triton X-100, $1 \mathrm{mM}$ DTT, $2 \mathrm{mM}$ EDTA, and $0.1 \mathrm{M}$ potassium phosphate, $\mathrm{pH} 7.8$ ) for $10 \mathrm{~min}$ on ice. Lysates were plated in duplicate onto 96-well plates with $20 \mu \mathrm{l}$ of $2 \mathrm{mM}$ Coenzyme A and $50 \mu \mathrm{l}$ of $2 \times$ luciferase assay buffer ( $6 \mathrm{mM} \mathrm{ATP,} 30 \mathrm{mM} \mathrm{MgSO}{ }_{4} \cdot 7 \mathrm{H}_{2} 0,20 \mathrm{mM}$ DTT, and $60 \mathrm{mM}$ Tricine, $\mathrm{pH}$ 7.8). Each well was injected with $50 \mu$ l of $2 \mathrm{mM}$ Luciferin (BD Biosciences, San Jose, CA, USA), and the relative luciferase activities were measured using the Ascent $L$ software. Raw luciferase values were normalized with cotransfected CMV- $\beta$ galactosidase (CMV- $\beta$-gal) using the Galacto-light Chemiluminescent Reporter Kit (Applied Biosystems, Foster City, CA, USA), according the manufacturer's protocol. At least three independent transfections were performed, and data presented are mean \pm standard error.

Quantitative reverse transcriptase PCR. Total RNA was extracted from cells using the Qiagen RNeasy Mini Kit (Qiagen, Valencia, CA, USA), and firststrand $c D N A$ was synthesized using the iScript RNase $H+c D N A$ Synthesis Kit (BioRad). Quantitative real-time PCR was performed using a Bio-Rad iCycler PCR machine (Bio-Rad). Each amplification reaction contained $1 \mu \mathrm{l}$ of CDNA template and $500 \mathrm{nM}$ of primers, and was topped to a final volume of $20 \mu \mathrm{l}$ with SYBR Green Supermix reagents (Bio-Rad). Quantitative real-time PCR was performed for 27 cycles $\left(94^{\circ} \mathrm{C}\right.$ for $30 \mathrm{~s}, 50^{\circ} \mathrm{C}$ for $30 \mathrm{~s}$, and $72^{\circ} \mathrm{C}$ for $\left.30 \mathrm{~s}\right)$. Endogenous BIN1 mRNA expression was normalized to that of GAPDH (glyceraldehyde 3-phosphate dehydrogenase) as an internal control. All RT-PCR reactions were performed in triplicate. All primers for RT-PCR used in this study were described previously. ${ }^{21}$

Chromatin immunoprecipitation. A total of $2 \times 10^{6}$ cells were treated with or without etoposide for $24 \mathrm{~h}$, and were then cross-linked with $3.7 \%$ formaldehyde (Sigma) at r.t. for $10 \mathrm{~min}$. Cells were incubated with $0.125 \mathrm{M}$ glycine to terminate cross-linking, washed twice with PBS, and lysed in SDS nuclear lysis buffer (1\% SDS, $10 \mathrm{mM}$ EDTA, and $50 \mathrm{mM}$ Tris- $\mathrm{HCl}, \mathrm{pH} 8.1$ ) for $10 \mathrm{~min}$ on ice. Sonicated lysates were diluted in ChIP dilution buffer $(0.01 \%$ SDS, $1.1 \%$ Triton $X$ 100, 1.2 mM EDTA, $167 \mathrm{mM} \mathrm{NaCl}$, and 16.7 mM Tris- $\mathrm{HCl}, \mathrm{pH}$ 8.1), and incubated with $10 \mu \mathrm{g}$ of rabbit IgG (Pierce) and protein A agarose beads overnight at $4^{\circ} \mathrm{C}$ with gentle rocking. The cleared supernatants were mixed with either $2 \mu \mathrm{g}$ of an antiE2F1 rabbit polyclonal antibody (sc-193X; Santa Cruz Biotechnology) or with preimmune rabbit lgG overnight at $4^{\circ} \mathrm{C}$. Antibody/protein/DNA complexes were coprecipitated with protein-A beads. Protein/DNA conjugates were eluted from the beads complexes using Elution buffer ( $100 \mathrm{mM} \mathrm{NaHCO}$ and $1 \%$ SDS) for $30 \mathrm{~min}$. Cross-links were reversed in $5 \mathrm{M} \mathrm{NaCl}$. RNA and protein were removed by incubation first with $10 \mu \mathrm{g}$ DNase-free RNase-A at $37^{\circ} \mathrm{C}$ for $1 \mathrm{~h}$, and then with $20 \mu \mathrm{g}$ proteinase $\mathrm{K}$ at $50^{\circ} \mathrm{C}$ for $4 \mathrm{~h}$. DNA was recovered by phenol/chloroform extraction and ethanol precipitation. A DNA fragment encompassing the indicated region of the human BIN1 promoter was amplified using 35 cycles of $\mathrm{PCR}$ at $94^{\circ} \mathrm{C}$ for $30 \mathrm{~s}, 55^{\circ} \mathrm{C}$ for $30 \mathrm{~s}$, and $72{ }^{\circ} \mathrm{C}$ for $30 \mathrm{~s}$. All amplified products were resolved on a $2 \%$ agarose gel. The following primers were used: $\mathrm{ChIP}(\gamma / \delta)$ (forward) $5^{\prime}$-TCCTGGGTTGCAGG AGAGTTACTGCT-3' and ChIP $(\gamma / \delta)$ (reverse) $5^{\prime}$-ACCGCCAGGTCCTTCTAGGAT-3'. All primer sequences tested in this study were determined empirically and were synthesized by Integrated DNA Technologies (Coralville, IA, USA).

\section{Cell-based assays}

Colony formation assay. LNCaP/pIRES (neo) or LNCaP/pIRES-AS-BIN1 (neo) cells were transfected with $2 \mu \mathrm{g}$ of pLPC control vector (puro), pLPC-E2F1 (puro), or pLPC-BIN1 (puro) in $60 \mathrm{~mm}$ dishes using the FuGENE6 DNA transfection reagent. At $48 \mathrm{~h}$ posttransfection, cells were trypsinized and diluted at a $1: 6$ ratio, and were then cultured for 2 weeks in growth medium containing $0.45 \mu \mathrm{g} / \mathrm{ml}$ of puromycin (from which untransfected cells were completely removed in a week). Surviving colonies were stained and scored using the Giemsa reagent (Invitrogen). ${ }^{10,12}$

Cell death assays. To assess whether growth defect could be attributed to apoptosis, we employed two assay methods. The first method was 4',6-diamino-2phenylindole (DAPI; Sigma) staining, which detects chromatin condensation. Cells harvested in PBS were transferred to poly-D-lysine-coated coverslips in six-well plates, and were then centrifuged at 500 r.p.m. using a swing bucket. Cells on coverslips were incubated with $3.7 \%$ formaldehyde (Sigma) for $10 \mathrm{~min}$ at r.t. and gently washed three times in PBS. Nuclei were stained in $1 \mu \mathrm{g} / \mathrm{ml}$ of DAPI for $5 \mathrm{~min}$ and were then visualized by fluorescence microscopy using a UV filter. The second method was the Annexin V binding assay. Annexin V binding to phosphatidyl serine residues exposed on the outer plasma leaflet of apoptotic cells was detected using the Vybrant Apoptosis Assay Kit (Invitrogen). In brief, cells seeded in $100 \mathrm{~mm}$ dishes were washed in ice-cold PBS, harvested, and centrifuged for $5 \mathrm{~min}$ at 1500 r.p.m. Cells were resuspended in $100 \mu \mathrm{l}$ of $1 \times$ Annexin V binding buffer and the cell count was adjusted to $1 \times 10^{6} \mathrm{cells} / \mathrm{ml}$. After addition of $10 \mu \mathrm{l}$ of Alexa Fluor 488 Annexin V staining, cells were incubated for $15 \mathrm{~min}$ at r.t. and mounted on glass slides. Apoptosis was detected by fluorescence microscopy using a fluorescein isothiocyanate (FITC) filter. All cell-based assays described in this study were repeated at least three times, and data presented are mean \pm standard error.

Acknowledgements. We thank Dr. K Helin, Dr. G Melino, and Dr. L Yamasaki for providing the HA-ER-E2F1 cDNA, the p73 $\beta$ cDNA, and the E2f1 (-/-) MEFs, respectively. We are obliged to members of the Stanley S Scott Cancer Center clerical offices for assistance in the preparation of the article. This work was supported in part by grants from the US Army Department of Defense Prostate Cancer Research Program (DAMD 17-02-1-0131), the Walther Cancer Foundation, the Wendy Will Case Cancer Fund, the Susan G Komen Breast Cancer Foundation, and the Louisiana Cancer Research Consortium Awards (to DS). EKC was the recipient of the Bowen Minority Fellowship, the Purdue Doctoral Fellowship, and the Ruth L Kirschstein National Research Service Awards for Individual Predoctoral Fellows (NIH F31).

1. Kovesdi I, Reichel R, Nevins JR. E1A transcription induction: enhanced binding of a factor to upstream promoter sequences. Science 1986; 231: 719-722.

2. DeGregori J, Kowalik T, Nevins JR. Cellular targets for activation by the E2F1 transcription factor include DNA synthesis- and G1/S-regulatory genes. Mol Cell Biol 1995; 15: 4215-4224.

3. Pierce AM, Gimenez-Conti IB, Schneider-Broussard R, Martinez LA, Conti CJ, Johnson DG. Increased E2F1 activity induces skin tumors in mice heterozygous and nullizygous for p53. Proc Natl Acad Sci USA 1998; 95: 8858-8863.

4. Weinberg RA. E2F and cell proliferation: a world turned upside down. Cell 1996; 85: 457-459.

5. Phillips AC, Vousden KH. E2F-1 induced apoptosis. Apoptosis 2001; 6: 173-182.

6. Iaquinta PJ, Lees JA. Life and death decisions by the E2F transcription factors. Curr Opin Cell Biol 2007; 19: 649-657.

7. Polager S, Ginsberg D. E2F - at the crossroads of life and death. Trends Cell Biol 2008; 18: 528-535.

8. Yamasaki L, Jacks T, Bronson R, Goillot E, Harlow E, Dyson NJ. Tumor induction and tissue atrophy in mice lacking E2F-1. Cell 1996; 85: 537-548.

9. Field SJ, Tsai FY, Kuo F, Zubiaga AM, Kaelin Jr WG, Livingston DM et al. E2F-1 functions in mice to promote apoptosis and suppress proliferation. Cell 1996; 85: 549-561.

10. Sakamuro D, Elliott KJ, Wechsler-Reya R, Prendergast GC. BIN1 is a novel MYCinteracting protein with features of a tumour suppressor. Nat Genet 1996; 14: 69-77.

11. Sakamuro D, Prendergast GC. New Myc-interacting proteins: a second Myc network emerges. Oncogene 1999; 18: 2942-2954.

12. Elliott $\mathrm{K}$, Sakamuro D, Basu A, Du W, Wunner W, Staller $P$ et al. Bin1 functionally interacts with Myc and inhibits cell proliferation via multiple mechanisms. Oncogene 1999; 18: 3564-3573.

13. DuHadaway JB, Sakamuro D, Ewert DL, Prendergast GC. Bin1 mediates apoptosis by C-Myc in transformed primary cells. Cancer Res 2001; 61: 3151-3156.

14. Elliott K, Ge K, Du W, Prendergast GC. The c-Myc-interacting adaptor protein Bin1 activates a caspase-independent cell death program. Oncogene 2000; 19: 4669-4684.

15. Lin WC, Lin FT, Nevins JR. Selective induction of E2F1 in response to DNA damage, mediated by ATM-dependent phosphorylation. Genes Dev 2001; 15: 1833-1844.

16. Ge K, Duhadaway J, Sakamuro D, Wechsler-Reya R, Reynolds C, Prendergast GC. Losses of the tumor suppressor BIN1 in breast carcinoma are frequent and reflect deficits in programmed cell death capacity. Int J Cancer 2000; 85: 376-383.

17. Ge K, Minhas F, Duhadaway J, Mao NC, Wilson D, Buccafusca R et al. Loss of heterozygosity and tumor suppressor activity of Bin 1 in prostate carcinoma. Int $J$ Cancer 2000; 86: 155-161.

18. Ge K, DuHadaway J, Du W, Herlyn M, Rodeck U, Prendergast GC. Mechanism for elimination of a tumor suppressor: aberrant splicing of a brain-specific exon causes loss of function of Bin1 in melanoma. Proc Natl Acad Sci USA 1999; 96: 9689-9694.

19. Prendergast GC, Muller AJ, Ramalingam A, Chang MY. BAR the door: cancer suppression by amphiphysin-like genes. Biochim Biophys Acta 2009; 1795: 25-36.

20. Wechsler-Reya R, Sakamuro D, Zhang J, DuHadaway J, Prendergast GC. Structural analysis of the human BIN1 gene. Evidence for tissue-specific transcriptional regulation and alternate RNA splicing. J Biol Chem 1997; 272: 31453-31458.

21. Kinney EL, Tanida S, Rodrigue AA, Johnson JK, Tompkins VS, Sakamuro D. Adenovirus E1A oncoprotein liberates c-Myc activity to promote cell proliferation through abating Bin1 expression via an Rb/E2F1-dependent mechanism. J Cell Physiol 2008; 216: 621-631.

22. Hardy S, Shenk T. E2F from adenovirus-infected cells binds cooperatively to DNA containing two properly oriented and spaced recognition sites. Mol Cell Biol 1989; 9 4495-4506.

23. Attwooll C, Lazzerini-Denchi E, Helin K. The E2F family: specific functions and overlapping interests. EMBO J 2004; 23: 4709-4716. 
24. Pineda-Lucena A, Ho CS, Mao DY, Sheng Y, Laister RC, Muhandiram R et al. A structurebased model of the $\mathrm{C}-\mathrm{Myc} / \mathrm{Bin} 1$ protein interaction shows alternative splicing of Bin1 and c-Myc phosphorylation are key binding determinants. J Mol Biol 2005; 351: 182-194.

25. Sears RC, Nevins JR. Signaling networks that link cell proliferation and cell fate. J Bio Chem 2002; 277: 11617-11620

26. Sakamuro D, Eviner V, Elliott KJ, Showe L, White E, Prendergast GC. c-Myc induces apoptosis in epithelial cells by both p53-dependent and p53-independent mechanisms. Oncogene 1995; 11: 2411-2418.

27. Leone $\mathrm{G}$, Sears $\mathrm{R}$, Huang $\mathrm{E}$, Rempel R, Nuckolls $\mathrm{F}$, Park $\mathrm{CH}$ et al. Myc requires distinct E2F activities to induce $S$ phase and apoptosis. Mol Cell 2001; 8: 105-113.

28. Qi Y, Gregory MA, Li Z, Brousal JP, West K, Hann SR. p19ARF directly and differentially controls the functions of c-Myc independently of p53. Nature 2004; 431: 712-717.

29. Wajapeyee N, Serra RW, Zhu X, Mahalingam M, Green MR. Oncogenic BRAF induces senescence and apoptosis through pathways mediated by the secreted protein IGFBP7. Cell 2008; 132: 363-374.

30. Frisch SM. Antioncogenic effect of adenovirus E1A in human tumor cells. Proc Natl Acad Sci USA 1991; 88: 9077-9081.

31. Frisch SM. E1a induces the expression of epithelial characteristics. J Cell Biol 1994; 127 1085-1096.

32. Frisch SM, Francis H. Disruption of epithelial cell-matrix interactions induces apoptosis. J Cell Biol 1994; 124: 619-626.

33. Hugo H, Ackland ML, Blick T, Lawrence MG, Clements JA, Williams ED et al. Epithelialmesenchymal and mesenchymal-epithelial transitions in carcinoma progression. $J$ Cell Physiol 2007; 213: 374-383.
34. Grooteclaes ML, Frisch SM. Evidence for a function of CtBP in epithelial gene regulation and anoikis. Oncogene 2000; 19: 3823-3828.

35. Drees BL, Sundin B, Brazeau E, Caviston JP, Chen GC, Guo W et al. A protein interaction map for cell polarity development. J Cell Biol 2001; 154: 549-571.

36. Routhier EL, Donover PS, Prendergast GC. Hob1+, the fission yeast homolog of Bin1, is dispensable for endocytosis or actin organization, but required for the response to starvation or genotoxic stress. Oncogene 2003; 22: 637-648.

37. Zelhof AC, Bao H, Hardy RW, Razzaq A, Zhang B, Doe CQ. Drosophila Amphiphysin is implicated in protein localization and membrane morphogenesis but not in synaptic vesicle endocytosis. Development 2001; 128: 5005-5015.

38. Lebowitz PF, Sakamuro D, Prendergast GC. Farnesyl transferase inhibitors induce apoptosis of Ras-transformed cells denied substratum attachment. Cancer Res 1997; 57 708-713.

39. DuHadaway JB, Du W, Donover S, Baker J, Liu AX, Sharp DM et al. Transformationselective apoptotic program triggered by farnesyltransferase inhibitors requires Bin1. Oncogene 2003; 22: 3578-3588.

40. Javier RT. Cell polarity proteins: common targets for tumorigenic human viruses. Oncogene 2008; 27: 7031-7046.

41. Chang MY, Boulden J, Sutanto-Ward E, Duhadaway JB, Soler AP, Muller AJ et al. Bin1 ablation in mammary gland delays tissue remodeling and drives cancer progression. Cancer Res 2007; 67: 100-107.

42. Chang MY, Boulden J, Katz JB, Wang L, Meyer TJ, Soler AP et al. Bin1 ablation increases susceptibility to cancer during aging, particularly lung cancer. Cancer Res 2007; 67: 7605-7612.

\section{Supplementary Information accompanies the paper on Cell Death and Differentiation website (http://www.nature.com/cdd)}

